\title{
Contribution of precipitation and reference evapotranspiration to drought indices under different climates
}

\author{
Sergio M. Vicente-Serrano ${ }^{1, *}$, Gerard Van der Schrier ${ }^{2}$, Santiago Beguería ${ }^{3}$, Cesar Azorin-Molina ${ }^{1}$, \\ Juan-I. Lopez-Moreno ${ }^{1}$ \\ ${ }^{1}$ Instituto Pirenaico de Ecología, Consejo Superior de Investigaciones Científicas (IPE-CSIC), \\ Spain, ${ }^{2}$ Royal Netherlands Meteorological Institute (KNMI), 3730 AE De Bilt, Netherlands. ${ }^{3}$ Estación \\ Experimental de Aula Dei (EEAD-CSIC), Zaragoza, \\ * Corresponding author: svicen@ipe.csic.es
}

Abstract. In this study we analyzed the sensitivity of four drought indices to precipitation (P) and reference evapotranspiration (ETo) inputs. The four drought indices are the Palmer Drought Severity Index (PDSI), the Reconnaissance Drought Index (RDI), the Standardized Precipitation Evapotranspiration Index (SPEI) and the Standardized Palmer Drought Index (SPDI). The analysis uses long-term simulated series with varying averages and variances, as well as global observational data to assess the sensitivity to real climatic conditions in different regions of the World. The results show differences in the sensitivity to ETo and P among the four drought indices. The PDSI shows the lowest sensitivity to variation in their climate inputs, probably as a consequence of the standardization procedure of soil water budget anomalies. The RDI is only sensitive to the variance but not to the average of $\mathrm{P}$ and ETo. The SPEI shows the largest sensitivity to ETo variation, with clear geographic patterns mainly controlled by aridity. The low sensitivity of the PDSI to ETo makes the PDSI perhaps less apt as the suitable drought index in applications in which the changes in ETo are most relevant. On the contrary, the SPEI shows equal sensitivity to $\mathrm{P}$ and ETo. It works as a perfect supply and demand system modulated by the average and standard deviation of each series and combines the sensitivity of the series to changes in magnitude and variance. Our results are a robust assessment of the sensitivity of drought indices to $\mathrm{P}$ and ETo variation, and provide advice on the use of drought indices to detect climate change impacts on drought severity under a wide variety of climatic conditions. 
32 Key-words: Palmer Drought Severity Index, Standardized Precipitation Evapotranspiration Index, 33 Reconnaissance Drought Index, Standardized Palmer Drought Index, evaporation, global warming.

\section{Introduction}

36 Determining the effect of climate change on drought severity is difficult due to the lack of long-term 37 series and accurate measurements of streamflows, soil moisture, lake levels, etc. This situation is made worse by the effects of water management and land transformation on these series, making a separation of a climatic and antrophogenic signal difficult. For this reason, the assessments of climate warming impacts on drought trends at the global scale have been based on climatic drought indices (e.g., Sheffield et al., 2012; Dai, 2013; Van der Schrier et al., 2013; Beguería et al., 2014), which can be computed for the entire world given the availability of global climate data. These indices are calculated from time series of precipitation $(\mathrm{P})$ and reference evapotranspiration (ETo), and in general they are good proxies to determine drought conditions in a variety of environmental, hydrological and agricultural systems (Vicente-Serrano et al., 2012).

The results of global studies analyzing the effect of warming processes on drought severity differ in

47 the magnitude of the drought trends and in their spatial patterns as a consequence of differences in the forcing precipitation data sets used (Trenberth et al., 2014), the models used to estimate ETo and the meteorological data sets used to calculate ETo. Sheffield et al. (2012) analyzed, at the global scale, the influence of using a simple empirical temperature-based formulation and a more physical model, based on several meteorological variables, to estimate ETo. They showed that, globally averaged, differences in the variability and change of drought indices may relate to the parameterization used to estimate ETo. Nevertheless, strong differences in the magnitude of ETo changes may be obtained using different methods to estimate ETo (e.g., Donohue et al., 2010;

Vicente-Serrano et al., 2014a, van der Schrier et al. 2013). 
These observations pose the question to the sensitivity of the different indices to variations in $\mathrm{P}$ and ETo; a matter which has seen only limited attention in the scientific literature A few studies based on the Palmer Drought Severity Index (PDSI) showed contradictory or opposite results. Guttman (1991) analysed the sensitivity of the Palmer Drought Hydrological Index (similar but slightly simpler than the PDSI) to P and ETo in USA, and found that the effect of temperature anomalies (used to obtain ETo) are insignificant compared to the effect of precipitation anomalies. On the contrary, Hu and Willson (2000) analyzed the sensitivity of the PDSI in central United States and showed that the PDSI can be equally affected by temperature and precipitation, when both have similar magnitudes of anomalies.

The Standardized Precipitation Index (SPI) (McKee et al., 1993) is put forward by the World Meteorological Organization (WMO) as universal drought index (Hayes et al., 2011; WMO, 2012). adapt to the varied response times of typical hydrological variables to precipitation deficits. It allows detecting different drought types that affect different systems and regions. Although the SPI has shown to be useful for drought monitoring and early warning (e.g., Hayes et al., 1999), deficiencies have also been noticed related to its inability to detect drought conditions determined not by a lack of very relevant under extreme heat waves (Beguería et al., 2014). For climate change studies, the inability of the SPI to capture an increased evaporative demand related to global warming is problematic as well (Dai, 2013; Beguería et al., 2014; Cook et al., 2014). For this reason, studies on recent drought trends (Sheffield et al., 2012; Vicente-Serrano et al., 2014b) and drought scenarios under future climate change projections (e.g., Hoerling et al., 2012; Cook et al., 2014) are based on drought indices that consider not only precipitation but also the atmospheric evaporative demand. Using these indices, Cook et al. (2014) showed that increased ETo not only intensifies drying in 
areas where precipitation is already reduced, it also drives areas into drought that would otherwise experience little drying or even wetting from precipitation trends alone.

In this study we analyze the relative contribution of variations in P and ETo to the spatial and temporal variability of four drought indices that make use of both variables in their calculation: (i) the self calibrated Palmer Drought Severity Index (PDSI) (Wells et al., 2004); (ii) the Reconnaissance Drought Index (RDI) (Tsakiris et al., 2007); (iii) The Standardized Precipitation Evapotranspiration Index (SPEI) (Vicente-Serrano et al., 2010a); and (iv) the Standardized Palmer Drought Index (SPDI) (Ma et al., 2014). The analysis includes a theoretical assessment using longterm simulated series under different average and variance constraints for both P and ETo, and a global study based on gridded datasets and instrumental series from meteorological stations. The motivation to include these four indices is that they all are based on a combination of P and ETo which we think is more realistic than using only P. Temporal agreement between hydrological and climatic drought indices using ETo in their formulations is strong even considering different climate conditions (Lopez-Moreno et al., 2013; Lorenzo-Lacruz et al., 2013; Haslinger et al., 2014; Törnros and Menzel, 2014). In addition, the relationship of these indices with vegetation growth and activity, both highly determined by soil water availability, is quite strong (Orwing and Abrams, 1997; Vicente-Serrano et al., 2013; Ivits et al., 2014).

\section{Methods}

\subsection{Drought indices}

\section{a) The Palmer Drought Severity Index}

The PDSI (Palmer, 1965; Karl, 1983 and 1986; Alley, 1984) enables measuring both wetness (positive values) and dryness (negative values), based on the supply and demand concepts of the water balance equation, and thus incorporates prior precipitation, moisture supply, runoff, and evaporation demand at the surface level. Palmer (1965) used data from a few locations in the 
105 American mid-west to standardize the index, which restricts its application around the world (see 106 Akimremi et al., 1996; Guttman et al., 1992; Heim, 2002). This problem was solved by the self107 calibrated PDSI (Wells et al., 2004), which calibrates the PDSI using data specifically suitable for 108 each location, which makes it more spatially comparable. In this study we use the self-calibrated 109 version of the PDSI. There is a number of studies that have revised the advantages and limitations of 110 the PDSI for drought analysis and monitoring. On the positive side, it allows to measure both 111 wetness (positive values) and dryness (negative values), based on the supply and demand concepts of 112 the water balance equation, and thus incorporates prior precipitation, moisture supply, runoff and 113 evaporation demand at the surface level (Karl, 1983 and 1986; Alley, 1984). In addition to the above 114 mentioned problems of spatial comparability, other different issues and deficiencies in the use of the 115 PDSI for drought quantification and monitoring have been widely reviewed. They are related to its 116 sensitivity to the soil water field capacity (Karl, 1986; Weber and Nkemdirim, 1998) and its lack of 117 adaptation to the intrinsic multi-scalar nature of drought (Vicente-Serrano et al., 2011). Mishra and 118 Singh (2010) provided a revision of the advantages and limitations of different drought indices, and 119 they also stressed the limitations of the PDSI related to runoff underestimation and slow response to 120 developing and diminishing droughts.

\section{b) The Reconnaissance Drought Index}

123 The RDI (Tsakiris and Vangelis, 2005) is calculated with P and ETo and is based on the approach 124 similar to calculate the aridity index (AI); i.e., as the quotient between P and ETo (UNESCO, 1979), 125 which can be computed at different time-scales. This quotient is standardized according to the mean 126 and standard deviation of the series, assuming that P/ETo follows a log-normal distribution. 127 Interpretation of the RDI is similar to that of the SPI. The RDI has been used to assess drought 128 variability and trends in some regions (e.g., Khalili et al., 2011; Zarch et al., 2012; Baninahd and 129 Khalili, 2013; Vangelis et al., 2013). There are not studies that have analysed the advantages and 
shortcomings of the RDI, but among the main theoretical limitations of this drought index it is

highlighted that gives no valid values when ETo is equal to 0, which is very common in cold regions in winter, mainly when ETo is calculated using empirically temperature-based methods.

\section{c) The Standardized Precipitation Evapotranspiration Index}

135 Vicente-Serrano et al. (2010a, 2010b, 2011, 2012) and Beguería et al. (2014) provided complete descriptions of the theory behind the SPEI, the computational details, and comparisons with other popular drought indicators such as the PDSI and the SPI. The SPEI is based on a monthly climatic water balance (P-ETo), which is adjusted using a 3-parameter log-logistic distribution. The values are accumulated at different time scales and converted to standard deviations with respect to average values. Some authors have criticized the SPEI in relation to the PDSI arguing that the SPEI does not represent soil water content (Dai, 2011; Joetzjer, 2014) but the aim of the SPEI is to represent departures in climatological drought, the balance between the water availability and the atmospheric water demand, and is therefore slightly different from the drought índices that include a simplified soil moisture budget which relate their index to the latter quantity (see further discussion in Beguería et al., 2014).

d) The Standardized Palmer Drought Index

Recently, Ma et al. (2014) developed a drought index based on the mixture of the supply and demand concept of the PDSI while having the multi-scalar and statistical nature of the SPI and SPEI. The 150 SPDI is based on a moisture departure used to obtain the PDSI and a probabilistic approach. 151 Moisture departure is the difference between actual precipitation and a reference precipitation, which 152 Palmer (1965) referred to as 'Climatically Appropriate For Existing Conditions' (CAFEC). The 153 CAFEC precipitation is analogous to a simple water balance where precipitation is equal to ETo plus 154 runoff, plus or minus any change in soil moisture storage (Alley, 1984). 
155 Moisture departure is transformed to a standard normal variable, with mean equal to 0 and standard 156 deviation equal to 1 , fitting the observed moisture departures to a General Extreme Value 157 distribution. Authors argued advantages of the SPDI with respect to (i) the PDSI because it can be 158 calculated on different time-scales, and (ii) to the SPEI since more spatially uniform response to $\mathrm{P}$ 159 and ETo variations can be achieved. Ma et al. (2014) argued that SPEI responds differently to 160 temperature and precipitation variations for diverse climatic conditions, and indicated that this would 161 challenge the spatial consistency and comparability of the SPEI.

\subsection{Data sets}

164 To analyze the sensitivity of the four drought indices to P and ETo we used different data sources. 165 One is random surrogate series for P and ETo series corresponding to different average monthly magnitude (i.e. $20,50,75,100,150,200$ and $250 \mathrm{~mm} \mathrm{month}^{-1}$ ) and three levels of standard deviation (i.e. $10 \%, 25 \%$ and $50 \%$ of the average of the series) for each P and ETo averages. Following a simple Monte Carlo simulation, 100-year random series were generated independently from a normal distribution and a white noise process, which means serially uncorrelated random variables. The mean of the series were the seven monthly magnitudes indicated above and the three standard 171 deviation levels of the given magnitude. We generated 21 series (i.e. 7 different average magnitudes 172 x 3 different standard deviations) of $\mathrm{P}$ and ETo, and combined them as inputs to calculate the four 173 drought indices. Figure 1.A shows an example with the pdfs of simulated series corresponding to 174 different average monthly $\mathrm{P}$ magnitudes under three standard deviations. Figure $1 . \mathrm{B}$ shows an 175 example of 100 years evolution of simulated monthly precipitation with a monthly average of 100 $176 \mathrm{~mm}$ and three different standard deviations. A total of 441 combinations between the simulated $\mathrm{P}$ and 177 ETo series were used to calculate 100 years of drought indices. These conditions cover a wide range 178 of $\mathrm{P}$ and ETo regimes worldwide. 
180 (CRU) TS3.21 dataset (Harris et al., 2013, http://badc.nerc.ac.uk/; last accessed 1 September 2014),

which has a spatial resolution of $0.5^{\circ}$ and covers the period 1901-2011. ETo in the TS3.21 dataset is obtained using the FAO-56 Penman-Monteith equation (Allen et al., 1998). In this study we focused on the period 1950-2011 to avoid that low data availability in large regions of the world for the first half of the twentieth century affected the obtained results. The potential soil moisture storage capacity dataset is taken from the Food and Agriculture Organization digital soil map of the world (FAO, 2003) and regridded from $5^{\prime}$ to $0.5^{\circ}$ resolution by taking the water holding capacity of the most dominant soil type in the aggregated grid.

Simultaneosly, we used data from meteorological observatories recorded in world regions characterized by different climate conditions. Observed data was obtained from the Global Historical Climatology Network (GHCN-Monthly) database (http://www.ncdc.noaa.gov/oa/climate/ghcnmonthly/; last accessed 1 September 2014). Given availability limitations for some of the variables needed to calculate ETo using the Penman-Monteith method (wind speed, sunshine duration and relative humidity), we used mean temperature and estimated ETo using the Thornthwaite equation 194 (Thornthwaite, 1948). Because of the only dependence of this parameterization on temperature, this parameterization could affect drought trends (Sheffield et al., 2012). However, it does not effect on the sensitivity analysis applied in this study since only the magnitude and variance of ETo plays a role on this analysis, and the average magnitude and variance of Thornthwaite and Penman-Monteith ETo are similar at the global scale (van der Schrier et al., 2011; Sheffield et al., 2012).. The stations used for this analysis correspond to thirty-four observatories around the World for the period 19012007 of $\mathrm{P}$ and mean temperature data, having less than $5 \%$ of missing gaps. These observatories represent regions whose climates are classified as equatorial (Manaus and Quixeramobim) tropical (Tampa, Sao Paulo, Seychelles and Curitiba), monsoon (Indore, Calcutta, Bangkok, etc.), 203 Mediterranean (Valencia, Kimberley and Tripoli), semiarid (Albuquerque, Lahore and Saint-Louis), 
extreme arid (Khartoum), continental (Wien, Zurich, Winnemucca, Toccoa and Salta), cold

205 (Helsinki, Punta Arenas and Reykjavik) and oceanic (Abashiri, Lisboa, Uccle, Buenos Aires, 206 Smithfield, Olga and Smithfield) (Figure 2).

The simulated series allowed determining the theoretical sensitivity of the drought indices spatial gradients in P and ETo averages and standard deviations. using a wide range of climate conditions, while the observed climate series from observations and gridded datasets allowed determining the response under real conditions, considering the existing

\subsection{Experimental set-up}

214 combinations of $\mathrm{P}$ and ETo) and used the 12-month time-scale for computing the SPEI, RDI and 215 SPDI. Monthly values were used for subsequent analysis. The PDSI does not relate to one specific 216 time-scale (Guttman, 1998), but in general it can be associated with time-scales between 9-14 217 months in most regions of the world (Vicente-Serrano et al., 2010a and 2010b). For this reason, it is 218 expected that 12-month is a suitable time scale for SPEI, RDI and SPDI to be compared to the PDSI. 219 We also compared the series of the four drought indices among them calculating Pearson's $r$ 220 correlations. Higher (positive or negative) $\mathrm{r}$ values means higher (positive or negative) sensitivity of 221 the drought index to P or ETo. The analysis was applied to the indices obtained from the surrogate 222 series, gridded datasets and the observed station series. For PDSI and SPDI, information on the soil 223 moisture capacity is needed. For the surrogate series three values are used; $500 \mathrm{~mm}$ (i.e., the lowest 224 value in the Webb et al., 1993 dataset), $1000 \mathrm{~mm}$ and $2000 \mathrm{~mm}$ (i.e., the highest value in the Webb 225 et al., 1993 dataset). For the observatory series, a uniform value of $1000 \mathrm{~mm}$ is used as soil water 226 capacity.

227 In the gridded datasets we masked the desert areas by means of the GlobCover coverage 228 (http://due.esrin.esa.int/globcover/; last accessed 1 September 2014) since calculating drought indices 
229 in desert regions is meaningless. Moreover, there are methodological problems for their calculation 230 given high frequency of 0 values for precipitation and water balances (Wu et al., 2007; Beguería et 231 al., 2014).

232 Sensitivity of the four drought indices to variation in $\mathrm{P}$ and ETo was also assessed by means of the 233 correlation between the 12-month SPEI, RDI and SPDI with cumulative 12-month P and ETo series 234 used for their calculations. The exception was the PDSI since it does not represent a fixed time-scale. 235 For this reason we obtained correlations between the series of PDSI and series of P and ETo at time236 scales from 1- to 24-months retaining the maximum correlation, independently of the time-scale at 237 which it was recorded (see example in the Supplementary Figure 1). The results of these analyses 238 were compared with the average and standard deviation of P and ETo.

240 3. Results

\section{$241 \quad 3.1$ Relationship between drought indices}

242 The four drought indices correlated strongly with each other. Figure 3 shows correlations among the 243 PDSI, the RDI, the SPEI and the SPDI obtained from the 441 combinations of simulated P and ETo 244 series. The plots show correlations between the drought indices for ETo and P series with given 245 means and one of the three levels of standard deviation. For example, the upper left element of each 246 matrix corresponds to Pearson's $\mathrm{r}$ values for the P series having a standard deviation equal to $10 \%$ of 247 the average and ETo series having a standard deviation equal to $50 \%$ of the average. Correlation 248 between the PDSI and the other three drought indices was lower than found among the RDI, the 249 SPEI and the SPDI Pearson's r correlation coefficients between the PDSI and the RDI, the SPEI and 250 the SPDI vary between 0.5 and 0.8 . There are no clear patterns of correlation between PDSI and the 251 other three indices as a function of the average and standard deviation of $\mathrm{P}$ and ETo series. 252 Nevertheless, some features can be highlighted. For high average P and low average ETo values, the 253 correlation between the PDSI and the RDI is low, mostly for low P standard deviation. Higher 
correlations between the PDSI and the RDI are identified corresponding to high average ETo values.

255 Correlations coefficients between the PDSI and the SPEI are high corresponding to high ETo standard deviations. The lower correlations among these two drought indices are recorded for series of low means of $\mathrm{P}$ combined with high $\mathrm{P}$ standard deviation and high ETo average. The correlation matrices of Figure 3 show that for P and ETo series having similar averages the correlation between the PDSI and the RDI and the SPEI decreases noticeably for low values of the variability in P and high values in the variability of ETo. This could be related to the water balance algorithm used in the PDSI calculations, since this pattern is also identified in the SPDI, which shares the same algorithm with the PDSI. Moreover, since the magnitude of this pattern is different as a function of the soil water capacity (see Supplementary Figures 2 and 3) it is plausible that under these particular conditions (i.e., same average P and ETo) the PDSI is producing low correlated series with respect to statistical drought indices such as the RDI and the SPEI. On the contrary, correlation between the PDSI and the SPDI is maximum for series having the same P and ETo averages, with Person's correlation coefficients higher than 0.8 , independently of the standard deviation of the series. Correlations among the SPEI, the RDI and the SPDI are much higher than those identified with the PDSI. In general, the values are higher than 0.9 , independently of the average and standard deviation of $\mathrm{P}$ and ETo (with the exception of the SPDI from $\mathrm{P}$ and ETo series having the same average and standard deviation). The soil water capacity used to calculate the PDSI and the SPDI has not a noticeable influence in the correlations among the four drought indices (see Supplementary Figs. 2 and 3).

Pearson's $r$ coefficients among the different drought indices in the series of the 34 selected observatories show, in general, high coefficients (Table 1). Correlation coefficients between PDSI and RDI are similar to those between PDSI and SPEI. The majority of observations show slightly higher correlation coefficients between PDSI and SPDI. Correlations between SPEI and RDI are very strong in most of the observatories, showing coefficients higher than 0.95 , with the exception of 
the most arid observatories (Khartoum and Albuquerque) where correlations are 0.83. Correlations between the RDI and the SPEI, and the SPDI, are also high (usually higher than 0.90). The correlation between the SPEI and the SPDI is quite strong in the majority of observatories, varying between 0.75 in the most arid observatory (Khartoum) and 0.96-0.97 in observatories located in very humid regions (e.g., Manaus and Seychelles).

The spatial distribution of the Pearson's $r$ coefficients among the four drought indices at the global scale shows magnitudes that resemble those found from simulated series and observed series. Figure 4 displays the correlation coefficients between the four drought indices calculated at the global scale by means of the CRU-TS3.21 dataset. The PDSI shows lower correlation coefficients with the other drought indices. Moreover there are not clear spatial patterns with the exception of the lowest correlations with the RDI and the SPEI in the north of Canada. Correlations between the PDSI and the SPDI are also only slightly higher with no clear patterns and dominant patchy structure. Correlation between the RDI and the SPEI is very strong in most of the regions of the world, and this finding is also valid for correlations between the RDI and the SPDI and between the SPEI and the SPDI, with the exception of regions of central USA, central Europe and central Asia.

\subsection{Influence of $P$ and ETo on drought indices}

\subsubsection{Assessment with surrogate series}

Figure 5 shows the Pearson's r correlations between the PDSI obtained from surrogate series of $\mathrm{P}$ and ETo with different means and a standard deviation of $10 \%, 25 \%$ and $50 \%$ the mean value. The different plots show a clear gradient in the influence of P and ETo on the PDSI as a function of $\mathrm{P}$ and ETo average and standard deviation. The sensitivity of the PDSI to $\mathrm{P}$ is higher when mean values of ETo are lower than mean values of $\mathrm{P}$ with the PDSI a near-perfect reflection of $\mathrm{P}$ when ETo $<$ P. Low standard deviation (10\%) in ETo and high standard deviation (50\%) in P also makes the PDSI reflect $\mathrm{P}$ more. The correlation between PDSI and $\mathrm{P}$ is weakest when amplitude and 
variability of $\mathrm{P}$ are smaller than the corresponding values of ETo (upper left element of the matrix in Figure 5a) Comparing this element with its anti-symmetric counterpart, the lower-right element of the matrix in Figure 5b, shows that correlations in this latter figure are generally closer to zero. This means that the PDSI is not equally sensitive to P and to ETo. Moreover, differences in P and ETo deviations (25\% and $50 \%$ of the average) and low standard deviations in ETo. Conversely, for low means of $\mathrm{P}$, high mean values of ETo the sensitivity of the SPEI to $\mathrm{P}$ is low, especially when 
and the ETo is the opposite to that found for P; the highest negative correlations are recorded with ETo high magnitude and standard deviation.

Finally, Figure 8 shows correlations between the SPDI and 12-month P and ETo series for different average and standard deviations of $\mathrm{P}$ and ETo. It shows a mixed response when compared to that of the RDI and the SPEI. For high standard deviation of P and low standard deviation of ETo the SPDI does not show a noticeable sensitivity to the magnitude of P. Under these conditions, the Pearson's r coefficients are higher than 0.95 over the whole range of $\mathrm{P}$ magnitudes. Nevertheless, for P series having low standard deviation (i.e., 10\% of the average) and high ETo standard deviation, the SPDI shows sensitivity to variations in the average magnitude of P. A quasi-opposite pattern is found analyzing the correlation between the SPDI and ETo. Strong negative correlations are found between the SPDI and ETo for high ETo magnitudes and standard deviations. As observed for the PDSI, the soil water capacity has small influence on the sensitivity of the SPDI to P and ETo (see Supplementary Figures 6 and 7).

Differences in the Pearson r coefficient (Supplementary Figs. 8, 9 and 10) show that the SPEI and the SPDI are stronger linearly correlated with P than the PDSI. Also the relation between ETo and the SPEI is more direct than with the other indices investigated.

\subsubsection{Assessment of climate observations}

\section{a) Gridded datasets}

Figure 9 takes the analysis of Section 3.2.1 one step further and shows the correlation between the four drought indices and P and ETo at the global scale from the CRU TS21 dataset. This figure shows that the SPDI is strongest linearly related to precipitation, and the PDSI has the least strong linear relation with precipitation. SPEI and RDI have slightly less strong correlations with precipitation than SPDI, especially at high latitudes and, for the SPEI, in dry areas. The spatial pattern could be due to the different magnitude and standard deviation of $\mathrm{P}$ and ETo series recorded 
353 at a global scale (see Supplementary Figure 11). P reaches higher average values than ETo but the 354 most relevant issue is that $\mathrm{P}$ has higher standard deviations than ETo. This pattern would explain that 355 although some of the drought indices respond theoretically equal to P and ETo (e.g., SPEI and RDI) 356 the observed correlation between drought indices and $\mathrm{P}$ is usually higher than between drought and 357 ETo. This is also observed for the PDSI and the SPDI in the majority of observatories and gridded 358 datasets. Correlation between the four drought indices and P shows high Pearson's $r$ coefficients in 359 large parts of the world for the SPEI, the RDI and the SPDI, with the pattern more uniformly high for 360 the SPDI reaching values over 0.95 for almost all world regions. Correlations between the RDI and P 361 are also high in most of the world, with the exception of boreal regions in North Eurasia and North 362 America. The pattern of correlation between the SPEI and P is more complex, with regions in the different continents showing correlations lower than 0.85. Correlations between the PDSI and P 364 show much lower magnitude than those found for the other three indices (i.e., varying between 0.65 and 0.85 ) and a patchy behavior characterized by strong spatial diversity in correlations. Correlations between the PDSI and $\mathrm{P}$ are lower than those found with the other three drought indices 367 (Supplementary Figure 12). It also shows how differences are higher with the SPDI, which shares the same soil water balance approach with the PDSI, and how differences do not show a clear spatial structure. The differences of correlation between the SPEI, the SPDI and the RDI and P are much lower. The correlations between the four drought indices and ETo show more diversity and clear 371 spatial patterns than those found for $\mathrm{P}$. The magnitude of correlations is usually lower than for $\mathrm{P}$, and 372 there are more differences among the four indices. The magnitude of correlations with ETo is higher 373 for the SPEI than for the rest of the indices, whereas the PDSI shows, again, the lowest correlations. 374 The four drought indices show lowest correlations in equatorial and boreal regions while maximum 375 correlations are recorded in central Asia, North America, South Africa and Australia. In contrast to 376 what is observed for P, the differences between the SPDI and the PDSI are generally low at the 377 global scale with minor regional differences (Supplementary Figure 13). In the semiarid regions of 
378 North and South America, Africa, Australia and central Asia the SPEI shows stronger correlations 379 with ETo than those found between ETo and the RDI. The opposite is found in equatorial and boreal regions in which correlations are stronger considering the RDI.

\section{b) Meteorological observatories}

The patterns with strong and weak correlations between the drought indices and aggregated $\mathrm{P}$ and ETo as discussed in Section 3.2.2 are also found with the series of observatories (see

Supplementary Table 1). Maximum correlation between the PDSI and P is recorded in Manaus (Pearson's $r=0.85)$. Minimum correlation between the PDSI and ETo is found in Wien $(r=-0.76)$. In areas with high ETo (e.g., Khartoum, Saint-Louis and Bangkok) the response of the PDSI to variations in ETo is close to zero. Correlations between the RDI and the SPDI with P are also in general higher than those obtained with the SPEI. On the contrary, the SPEI shows more negative correlations with ETo in the majority of observatories in relation to the other three drought indices.

Table 2 shows linear $\mathrm{R}^{2}$ coefficients between the correlations of the four drought indices with $\mathrm{P}$ and ETo (dependent variable) and the average and standard deviation of $\mathrm{P}$ and ETo from the observatories and gridded datasets (independent variable). The purpose of this analysis is to determine whether the spatial differences in the observed sensitivity of the four drought indices to P and ETo are related to the magnitude and variability of the two input variables.

Figure 10 shows some representative examples of the relationship between these variables 397 from both gridded datasets and meteorological observatories. Correlation of the PDSI with P (Plot D) 398 does not show a clear relationship with climate characteristics, since although it shows a $\mathrm{R}^{2}$ coefficient of 0.37 with the standard deviation of $\mathrm{P}$, this must be due to low data sampled since the coefficient obtained from the gridded data is close to zero. Correlation between the PDSI and ETo

(Plot E) shows a negative relationship with ETo average and standard deviation. It means that areas in which the PDSI is more affected by the ETo variability correspond to areas with high magnitude 
and/or standard deviation of ETo. The spatial pattern of correlations between the RDI and P (Plot C) 404 is mainly determined by the average ETo, with a non-linear relationship. Although the series of 405 observatories show a $\mathrm{R}^{2}$ coefficient equal to 0.35 between the correlation of the RDI vs. ETo and the average ETo (see Table 2), this is not recorded in the gridded dataset $\left(R^{2}=0.05\right.$, see Table 2$)$. 407 Among the four drought indices, the SPEI shows the best control of the average magnitude and variance of $\mathrm{P}$ and ETo to explain variations in its response to $\mathrm{P}$ and ETo variability (Figure 10, Plots 409 A, B and Table 2). Moreover, the results are consistent between the observatories and gridded datasets. Results are also in agreement with those expected from the sensitivity analysis reported previously. The response of the SPEI to $\mathrm{P}$ is clearly determined by the average and standard deviation of $\mathrm{P}$, both in the series of observatories and in the gridded data. The relationship is clearly non-linear (Figure 10, Plot G), showing that in areas of high P the SPEI is mostly determined by the variability of $\mathrm{P}$. The SPEI response to ETo is also controlled by the spatial pattern of $\mathrm{P}$ and ETo, with consistent results between the observatories and gridded datasets (Figure 10, Plots B and H). There is a linear positive relationship between the SPEI vs. ETo correlation and the average P, which shows that in areas with low $\mathrm{P}$ the correlation between $\mathrm{P}$ and ETo tends to be higher. Finally, the sensitivity of the SPDI to $\mathrm{P}$ does not show clear patterns related to the average and standard deviation of P series (see Table 2). The response to ETo shows a control similar to that found for the PDSI (Figure 10, Plot K), with a negative relationship with ETo standard deviation (Plot L).

\section{Discussion}

This study analyzed the sensitivity of four widely used drought indices to precipitation $(\mathrm{P})$ and reference evapotranspiration (ETo). The four drought indices (Palmer Drought Severity Index PDSI-, Reconaissance Drought Index -RDI-, Standardized Precipitation Evapotranspiration Index SPEI- and the Standard Palmer Drought Index -SPDI-) are calculated based on these two 427 parameters. Using surrogate series covering a wide range of $\mathrm{P}$ and ETo means and standard 
deviations, we showed that the PDSI and the SPDI show a more complex correlation pattern when compared with the other drought indices RDI and SPEI. The relation between drought indices is generally strong, except when compared with the PDSI, which correlates noticeably lower. This is demonstrated in Figure 5, which shows a band of strong correlations between SPDI and PDSI on the diagonal, whereas correlations between SPDI and mainly PDSI with the other drought indices are weak on the diagonal. We relate this to the use of the soil water balance algorithm which SPDI and PDSI share. On the diagonal, amplitude and variance of both P and ETo are similar. This results in a situation where $\mathrm{P}$, on average, nearly perfectly balances ETo making the CAFEC precipitation nearly equal to the actual P. The value of the moisture departure, the difference between actual and CAFEC precipitation is therefore small and minute changes in the runoff term or in the storage terms in the water balance will impact the moisture departure significantly, making its relation with $\mathrm{P}$ and ETo less direct. SPDI and PDSI, both based on the moisture departure, will remain correlated but RDI and SPEI, based on P and ETo will then correlate less strongly with either SPDI or PDSI. In addition, this study confirms earlier findings (Briffa et al., 1994, Dai et al., 1998, van der Schrier et al. 2006) that the PDSI does not show noticeable differences of sensitivity to P and ETo for different levels of soil water capacity. This suggests that although the PDSI follows a physically based soil water balance model, the influence of the soil water capacity on PDSI variability is low in relation to the influence of $\mathrm{P}$ and ETo.

The SPEI, the RDI and the SPDI all show high correlations for a range of P and ETo averages and standard deviations. This is also observed using long time series of meteorological observations under different climates and in the global gridded datasets. An exception to these strong correlations is, again, the PDSI, which shows lower correlations of around 0.75 with the other three indices under different theoretical conditions and with the series of observatories and gridded datasets. The PDSI is apparently more distantly related to either $\mathrm{P}$ or ETo than the other indices where almost linear relations with P and ETo are observed. Moreover, although the PDSI and the SPDI are related via the 
moisture departure, we have not found a strong agreement between these two, whereas all indices (excluding the PDSI) are found to be rather strongly related This must be related to the standardization of the moisture departure $d$ used in the PDSI which differs with that of SPDI and makes the relation of PDSI with the drivers of drought, $\mathrm{P}$ and ETo, less direct. The SPDI is based on a standardization of $d$ based on the fit to a probability distribution (Ma et al., 2014) whereas the PDSI uses a more complex way to standardize $d$. The procedure to standardize $d$ apparently strongly influences the resulting drought index. This was demonstrated earlier by Wells et al. (2004). There is a second reason why the PDSI correlates less strongly with the drivers of drought (and with the other drought indices used in this study). To determine if a wet or dry spell has ended, Palmer (1965) kept track of three different indices in the algorithm to which he related the end (or start) of a spell. Application of this criterion in the determination of whether a dry or wet spell has ended, may lead to a revision of previously computed PDSI values. This retrospective element in the PDSI calculations is referred to as 'backtracking' (Wells et al., 2004; van der Schrier et al., 2006) and further dilutes a direct relation between the drought index and its drivers.

The strong correlations found between the SPDI, the SPEI and the RDI and the weaker correlations of these indices with the PDSI indicates that differences between the PDSI and the other drought indices is not only due to the physical basis of the soil water balance model on which the PDSI is based, but also on the methodology to accumulate and standardize the precipitation surplus and deficit.

Differences between RDI and SPEI are found in their relation to ETo, with SPEI being much more sensitive to changes in ETo than RDI. This is confirmed with the observatory and gridded data used in this study. Although there were no previous studies analyzing the sensitivity of the RDI to both P and ETo inputs, the strong correlation shown in some studies between the RDI and the SPI, which is based on precipitation data only (Pearson's r $>0.98$, e.g., Tsakiris et al., 2007; Zarcch et al.,2012) already indicated that the RDI has a low sensitivity to ETo and high sensitivity to P. 
When considering the sensitivity of the four drought indices used in this study to P or ETo 479 changes on a global scale, the very high correlation between P and SPDI stands out. With correlations generally $>0.95$, it is difficult to see what this index adds to the use of the Standardized

481 Precipitation Index in which only P is standardized. The correlation patterns between P and SPEI or $482 \mathrm{P}$ and RDI are similar in structure, although the RDI seems slightly stronger correlated. At high 483 latitudes, where small values of ETo and P are found, both indices show weaker correlations with $\mathrm{P}$ 484 than on the rest of the globe. The PDSI shows much lower correlations with P, which is shown to be 485 related to the standardization used in this index.

Not surprisingly, the correlations between ETo and the PDSI or SPDI are very similar (with those of SPDI slightly stronger) given the shared use of the water balance model in their formulation. The relation between ETo and SPEI is the strongest of the four indices used. Recently, Cook et al. (2014) used the PDSI and the SPEI to determine 21th century drying by means of GCMs at the global scale. They observed, similar to the observations made in this study, that the SPEI was more sensitive to ETo changes than the PDSI, especially in arid regions such as the Sahara and the Middle East. Cook et al. (2014) also stressed that drying is more severe in the SPEI projections for the 21th century than those using the PDSI. When interpreting drought as an imbalance between water availability and the water demand, the SPEI is the more direct measure whereas the PDSI is more directly related to soil water availability. We have not been able to reproduce the result of Ma et al. (2014) that in humid sites no relation exists between the SPEI and ETo. Such relation was found for the surrogate data sets, the data from observational sites and the global gridded datasets. Figure 9 shows that in the tropics, the correlation between SPEI and ETo is stronger than that between SPDI and ETo. Thus, the sensitivity of SPEI to changes in P and ETo average and variance contradicts the statement raised by Ma et al. (2014). They concluded that P and temperature (used to calculate ETo) would contribute almost equally to the formulation of water surplus/deficit in both the PDSI and the SPDI, but not in the SPEI. 


\section{Conclusions}

- The four drought indices show sensitivity to P and ETo variations. Nevertheless, the degree and nature of this sensitivity varies noticeably among them.

- The RDI does not show sensitivity to variations in the magnitude of $\mathrm{P}$ and ETo which relates to the nature of this index. Using the quotient of $\mathrm{P}$ and ETo as input to a standardization cancels the amplitude of the drivers of drought. According to the results obtained in this study, under a climate change scenario where both $\mathrm{P}$ and ETo increase (as in northern Europe, e.g., Kaste et al., 2006) RDI would show a muted response, which means strong limitation for drought analysis and monitoring.

- The SPDI shows a strong sensitivity to P much higher than the PDSI. This indicates that the standardization procedure may affect the relation between drought index and the drivers of drought in a more important way than the used soil water balance algorithm since both indices uses the same algorithm.

- The PDSI is more sensitive to P than to ETo. Correlation between the PDSI and ETo shows substantially lower correlation than correlation between the SPEI and ETo, being this difference higher in arid and semiarid regions. This relates to the water balance model which is at the basis of the PDSI. The actual evapotranspiration (ETa), which enters the algorithm to calculate PDSI, is limited by precipitation rather than ETo in water stressed situations. This makes that the PDSI decouples from ETo values in situations where ETo > P (van der Schrier et al., 2013). The low sensitivity of the PDSI to ETo makes the PDSI perhaps less apt as the suitable drought index in applications in which the changes in ETo are most relevant.

- The SPEI shows equal sensitivity to P and ETo. It works as a perfect supply and demand system modulated by the average and standard deviation of each series. In contrast to the RDI that only shows sensitivity to variations on the standard deviation, the SPEI combines the 
sensitivity of the series to changes in magnitude and variance. Although there are combinations of $\mathrm{P}$ and ETo in which sensitivity to one of these drivers is stronger than the

\section{Acknowledgements}

548 This work has been supported by research project CGL2011-27574-CO2-02 financed by the Spanish 549 Commission of Science and Technology and FEDER and "Demonstration and validation of 550 innovative methodology for regional climate change adaptation in the Mediterranean area (LIFE 551 MEDACC)" financed by the LIFE programme of the European Commission. C. A-M was supported 552 by the JCI-2011-10263 postdoctoral fellowship by the Spanish Government. 


\section{References}

Akinremi, O.O., McGinn, S.M., and Barr, A.G., (1996): Evaluation of the Palmer Drought Index on the canadian praires. Journal of Climate, 9: 897-905.

Allen RG, Pereira LS, Raes D, Smith M. (1998): Crop Evapotranspiration: Guidelines for Computing Crop Requirements, Irrigation and Drainage Paper 56. FAO: Roma, Italia.

Alley, W.M., (1984): The Palmer drought severity index: limitations and applications. Journal of Applied Meteorology, 23: 1100-1109.

Banimahd, S.A., Khalili, D. (2013): Factors Influencing Markov Chains Predictability Characteristics, Utilizing SPI, RDI, EDI and SPEI Drought Indices in Different Climatic Zones. Water Resources Management 27: 3911-3928.

Beguería, S., Vicente-Serrano, S.M., Fergus Reig, Borja Latorre (2014). Standardized Precipitation Evapotranspiration Index (SPEI) revisited: parameter fitting, evapotranspiration models, kernel weighting, tools, datasets and drought monitoring. International Journal of Climatology, 34: 3001-3023.Briffa, K. R., Jones, P. D., Hulme, M., (1994) Summer moisture variability across Europe, 1892-1991: An analysis based on the Palmer Drought Severity Index. Intern. J. Climatology 14:475-506

Burke, E.J. (2011): Understanding the Sensitivity of Different Drought Metrics to the Drivers of Drought under Increased Atmospheric CO2. Journal of Hydrometeorology 12: 1378-1394.

Cai, W. and Cowan, T., (2008): Evidence of impacts from rising temperature on inflows to the Murray-Darling Basin. Geophysical Research Letters, 35, L07701, doi:10.1029/2008GL033390.

Chaves MM, Maroco JP, Pereira JS (2003) Understanding plant responses to drought—From genes to the whole plant. Funct Plant Biol 30(3):239-264.

Cook, B.I., Smerdon, J.E., Seager, R. et al., (2014): Global warming and 21st century drying. Climate Dynamics. 10.1007/s00382-014-2075-y.

Dai, A., Trenberth, K. E., Karl, T., (1998) Global variations in droughts and wet spells: 1900-1995, Geophys. Res. Lett. 25:3367-3370.

Dai, A., (2011): Characteristics and trends in various forms of the Palmer Drought Severity Index (PDSI) during 1900-2008. Journal of Geophysical Research-Atmosphere. doi:10.1029/2010JD015541.

Dai, A., (2013): Increasing drought under global warming in observations and models. Nature Climate Change, 3: 52-58.

Donohue, R.J., McVicar, T., Roderick, M.L., (2010): Assessing the ability of potential evaporation formulations to capture the dynamics in evaporative demand within a changing climate. Journal of Hydrology 386: 186-197.

Guttman, N.B., (1991): A sensitivity analysis of the Palmer Hydrologic Drought Index.Water Resources Bulletin, 27: 797-807.

Guttman, N.B., Wallis, J.R. and Hosking, J.R.M., (1992): Spatial comparability of the Palmer Drought Severity Index. Water Resources Bulletin. 28: 1111-1119.

Guttman, N.B., 1998: Comparing the Palmer drought index and the Standardized Precipitation Index. Journal of the American Water Resources Association, 34, 113-121.

Harris, I., Jones, P.D., Osborn. T.J. and Lister, D.H., (2014): Updated high-resolution grids of monthly climatic observations - the CRU TS3.10 Dataset, 34: 623-642.

Haslinger, K., D. Koffler, W. Schöner, and G. Laaha (2014), Exploring the link between meteorological drought and streamflow: Effects of climate-catchment interaction, Water Resour. Res., 50, doi:10.1002/2013WR015051. 
Hayes, M., Wilhite, D.A., Svoboda, M. and Vanyarkho, O., (1999): Monitoring the 1996 drought using the Standardized Precipitation Index. Bulletin of the American Meteorological Society 80: 429-438.

Hayes, M., Svoboda, M., Wall, N. and Widhalm, M., (2011): The Lincoln Declaration on Drought Indices: Universal Meteorological Drought Index Recommended. Bulletin of the American Meteorological Society, 92: 485-488.

Heim, R.R., (2002): A review of twentieth-century drought indices used in the United States. Bulletin of the American Meteorological Society. 83: 1149-1165.

Hoerling, Martin P., Jon K. Eischeid, Xiao-Wei Quan, Henry F. Diaz, Robert S. Webb, Randall M. Dole, David R. Easterling, 2012: Is a Transition to Semipermanent Drought Conditions Imminent in the U.S. Great Plains?. J. Climate, 25, 8380-8386.

$\mathrm{Hu}$, Q. and Willson, G.D., (2000): Effect of temperature anomalies on the Palmer drought severity index in the central United States. International Journal of Climatology. 20: 1899-1911.

Ivits, E., Horion, S., Fensholt, R. and Cherlet, M. (2014), Drought footprint on European ecosystems between 1999 and 2010 assessed by remotely sensed vegetation phenology and productivity. Global Change Biology, 20: 581-593. doi: 10.1111/gcb.12393

Joetzjer, E., Douville, H., Delire, C., Ciais, P., Decharme, B. and Tyteca, S., (2013): Hydrologic benchmarking of meteorological drought indices at interannual to climate change timescales: a case study over the Amazon and Mississippi river basins. Hydrol. Earth Syst. Sci., 17, 4885-4895.

Karl, T.R., (1983): Some spatial characteristics of drought duration in the United States. Journal of Climate and Applied Meteorology, 22: 1356-1366.

Karl, T.R., (1986): The sensitivity of the Palmer Drought Severity Index and the Palmer z-Index to their calibration coefficients including potential evapotranspiration. Journal of Climate and Applied Meteorology, 25: 77-86.

Kaste, Ø., Wright, R.F., Barkved, L.J., Bjerkeng, B., Engen-Skaugen, T., Magnusson, J. and Sælthun, N.R. (2006): Linked models to assess the impacts of climate change on nitrogen in a Norwegian river basin and fjord system. Science of the Total Environment, 365: 200-222. Khalili, D., Farnoud, T., Jamshidi, H., et al., (2011): Comparability Analyses of the SPI and RDI Meteorological Drought Indices in Different Climatic Zones. Water Resources Management 25: 1737-1757.

Lespinas, F., Ludwig, W. and Heussner, S., (2010): Impact of recent climate change on the hydrology of coastal mediterranean rivers in Southern France. Climatic Change, 99: 425-456.

Liang, S., Ge, S., Wan, L. y Zhang, J., (2010): Can climate change cause the Yellow River to dry up?. Water Resources Research, 46, W02505, doi:10.1029/2009WR007971.

López-Moreno, J.I., S.M., Vicente-Serrano, J. Zabalza, S. Beguería, J. Lorenzo-Lacruz, C. AzorinMolina, E. Morán-Tejeda. (2013): Hydrological response to climate variability at different time scales: a study in the Ebro basin. Journal of Hydrology. 477: 175-188.

Lorenzo-Lacruz, J., Vicente-Serrano, S.M., González-Hidalgo, J.C., López-Moreno, J.I., Cortesi, N. (2013) Hydrological drought response to meteorological drought at various time scales in the Iberian Peninsula. Climate Research. 58, 117-131

Ma, M., Liliang Ren, Fei Yuan, Shanhu Jiang, Yi Liu, Hao Kong, Luyan Gong (2014): A new standardized Palmer drought index for hydro-meteorological use. Hydrological Processes, DOI: $10.1002 /$ hyp.10063.

McKee, T.B.N., Doesken, J. and Kleist, J., (1993): The relationship of drought frecuency and duration to time scales. Eight Conf. On Applied Climatology. Anaheim, CA, Amer. Meteor. Soc. 179-184.

Mishra, A.K. and Singh, V.P., (2010): A review of drought concepts. Journal of Hydrology, 391: 202-216. Orwig, D.A., Abrams, M.D. 1997. Variation in radial growth responses to drought among species, site, and canopy strata. Trees: Structure and Function 11: 474-484. 
Sheffield, J., and E. F. Wood, 2007: Characteristics of global and regional drought, 1950-2000: Analysis of soil moisture data from off-line simulation of the terrestrial hydrologic cycle. J. Geophys. Res., 112, D17115, doi:10.1029/2006JD008288.

Sheffield, J., Wood, E.J., and Roderick, M.L. (2012): Little change in global drought over the past 60 years. Nature 491: 435-438.

Thornthwaite, C.W., 1948: An approach toward a rational classification of climate. Geographical Review, 38, 55-94.

Törnros, T. and L. Menzel (2014): Addressing drought conditions under current and future climates in the Jordan River region Hydrol. Earth Syst. Sci., 18, 305-318.

Trenberth, K.E., Dai, A., van der Schrier, G., et al. (2014): Global warming and changes in drought. Nature Climate Change 4: 17-22.

Tsakiris, G., D Pangalou, H Vangelis (2007): Regional drought assessment based on the Reconnaissance Drought Index (RDI). Water Resources Management 21, 5: 821-833.

United Nations Educational, Scientific and Cultural Organization (UNESCO). (1979). Map of the world distribution of arid regions: Map at scale 1:25,000,000 with explanatory note. MAB Technical Notes 7, UNESCO, Paris

van der Schrier, G., Barichivich, J., Briffa, K. R, Jones, P.D. (2013): A scPDSI-based global data set of dry and wet spells for 1901-2009. Journal of Geophysical Research-Atmospheres 118: 4025-4048.

van der Schrier, G., Briffa, K. R., Jones, P. D., Osborn, T. J. (2006) Summer moisture variability across Europe. J. Climate 19(12):2828-2834.

van der Schrier, G. , Jones, P. D. Briffa, K. R. (2011) The sensitivity of the PDSI to the Thornthwaite and Penman-Monteith parameterizations for potential evapotranspiration. Journal of Geophysical Research-Atmospheres 116: D03106, doi:10.1029/2010JD015001

Vangelis, H. , Tigkas, D. , Tsakiris, G. (2013): The effect of PET method on Reconnaissance Drought Index (RDI) calculation. Journal of Arid Environments 88: 130-140.

Vicente-Serrano S.M., Santiago Beguería, Juan I. López-Moreno, (2010a) A Multi-scalar drought index sensitive to global warming: The Standardized Precipitation Evapotranspiration Index SPEI. Journal of Climate 23: 1696-1718.

Vicente-Serrano, S.M., Beguería, S., López-Moreno, J.I., Angulo, M., El Kenawy, A. (2010b): A new global $0.5^{\circ}$ gridded dataset (1901-2006) of a multiscalar drought index: comparison with current drought index datasets based on the Palmer Drought Severity Index. Journal of Hydrometeorology 11: 1033-1043.

Vicente-Serrano, S.M., Beguería, S. and Juan I. López-Moreno (2011). Comment on "Characteristics and trends in various forms of the Palmer Drought Severity Index (PDSI) during 1900-2008" by A. Dai. Journal of Geophysical Research-Atmosphere. 116, D19112, doi:10.1029/2011JD016410.

Vicente-Serrano, S.M., Beguería, S., Lorenzo-Lacruz, J., et al., (2012): Performance of drought índices for ecological, agricultural and hydrological applications. Earth Interactions 16, 1-27.

Vicente-Serrano, S.M., Gouveia, C., Camarero, J.J. et al., (2013): The response of vegetation to drought time-scales across global land biomes. Proceedings of the National Academy of Sciences of the United States of America 110: 52-57.

Vicente-Serrano, S.M., Cesar Azorin-Molina, Arturo Sanchez-Lorenzo, Jesús Revuelto, Juan I. López-Moreno, José C. González-Hidalgo, Francisco Espejo. Reference evapotranspiration variability and trends in Spain, 1961-2011. Global and Planetary Change, 121: 2640.Vicente-Serrano, S.M., Juan-I. Lopez-Moreno, Santiago Beguería, Jorge Lorenzo-Lacruz, Arturo Sanchez-Lorenzo, José M. García-Ruiz, Cesar Azorin-Molina, Jesús Revuelto, Ricardo Trigo, Fatima Coelho, Francisco Espejo. (2014) Evidence of increasing drought severity caused by temperature rise in southern Europe. Environmental Research Letters. 9, 
044001. doi:10.1088/1748-9326/9/4/044001Wells, N., S. Goddard, and M.J. Hayes, (2004): A self-calibrating Palmer Drought Severity Index. Journal of Climate, 17, 2335-2351.

World Meteorological Organization. Standardized Precipitation Index User Guide (M. Svoboda, M. Hayes and D. Wood). (2012) (WMO-No. 1090), Geneva.

Wu, H., MD Svoboda, MJ Hayes, DA Wilhite, F Wen (2007). Appropriate application of the standardized precipitation index in arid locations and dry seasons. International Journal of Climatology 27, 65-79.

Yulianti, J.S. and Burn, D.H., (2006): Investigating links between climatic warming and low streamflow in the Prairies region of Canada. Geophysical Research Letters, 33: L20403.

Zarch, M.A.A., Malekinezhad, H., Mobin, M.H., Dastorani, M.T., Kousari, M.R. (2011): Drought Monitoring by Reconnaissance Drought Index (RDI) in Iran. Water Resources Management 25: 3485-3504.

\section{FIGURES AND TABLES}

A)

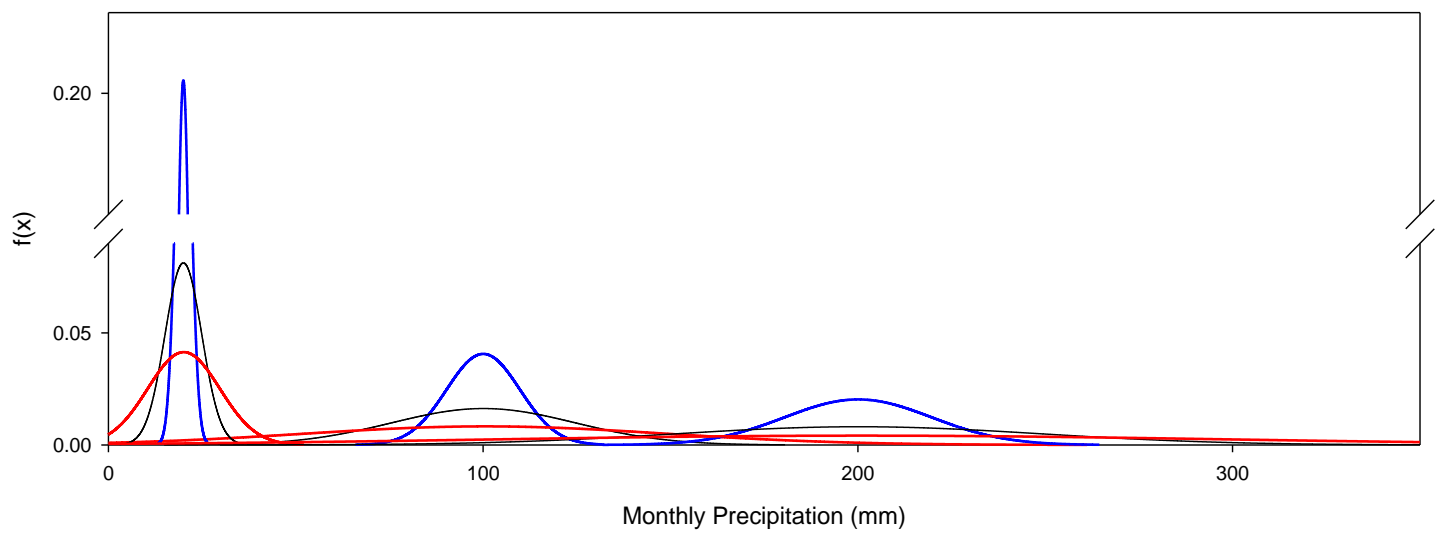

B) 

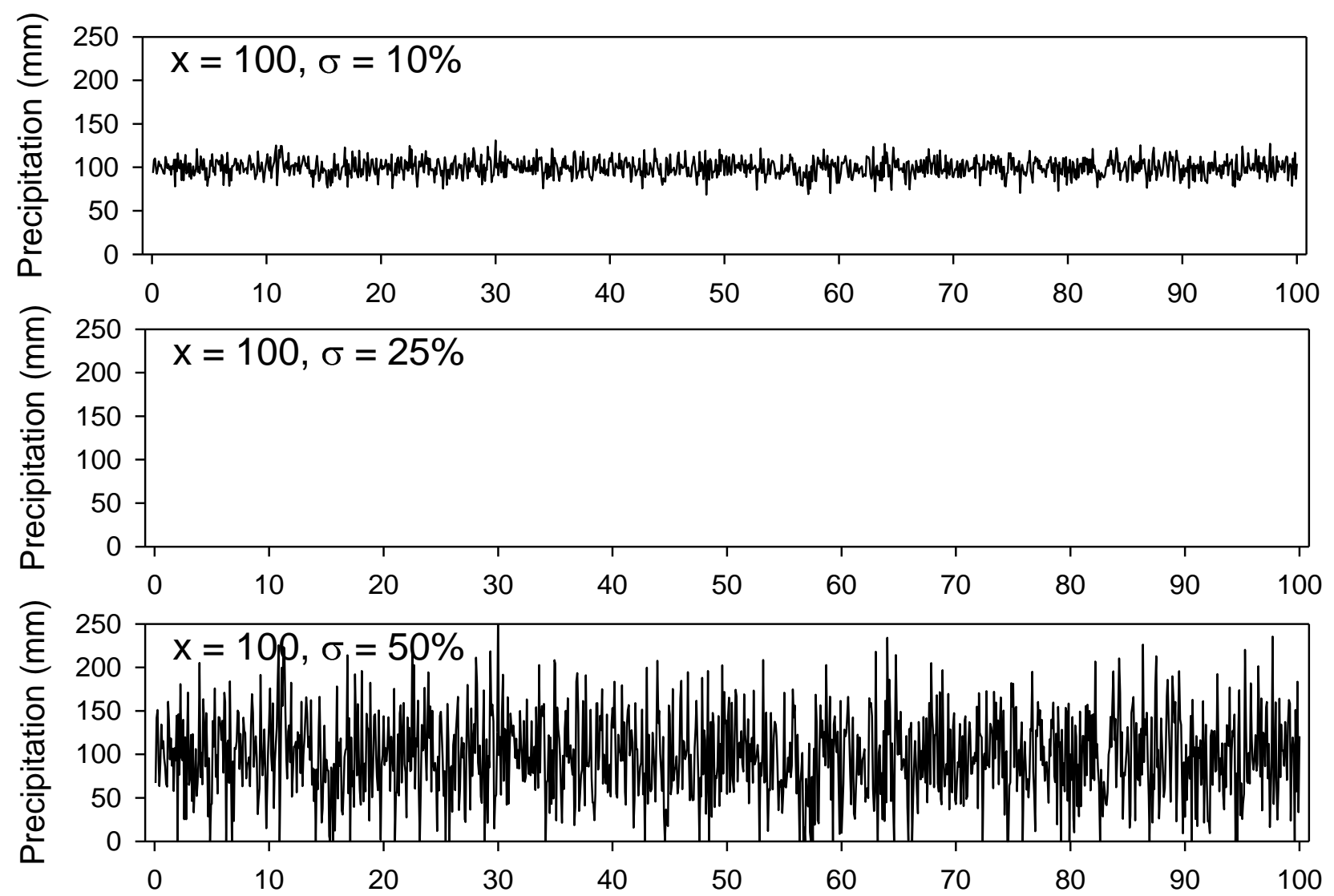

Figure 1. A) probability distribution functions (pdfs) of simulated monthly precipitation series with different averages and standard deviations (blue $=50 \%$ of the average, black $=25 \%$ of the average, red $=10 \%$ of the average). B) 100-years evolution of the simulated series of precipitation with average $=100 \mathrm{~mm}$ and standard deviation equal to $10 \%, 25 \%$ and $50 \%$ of the average.

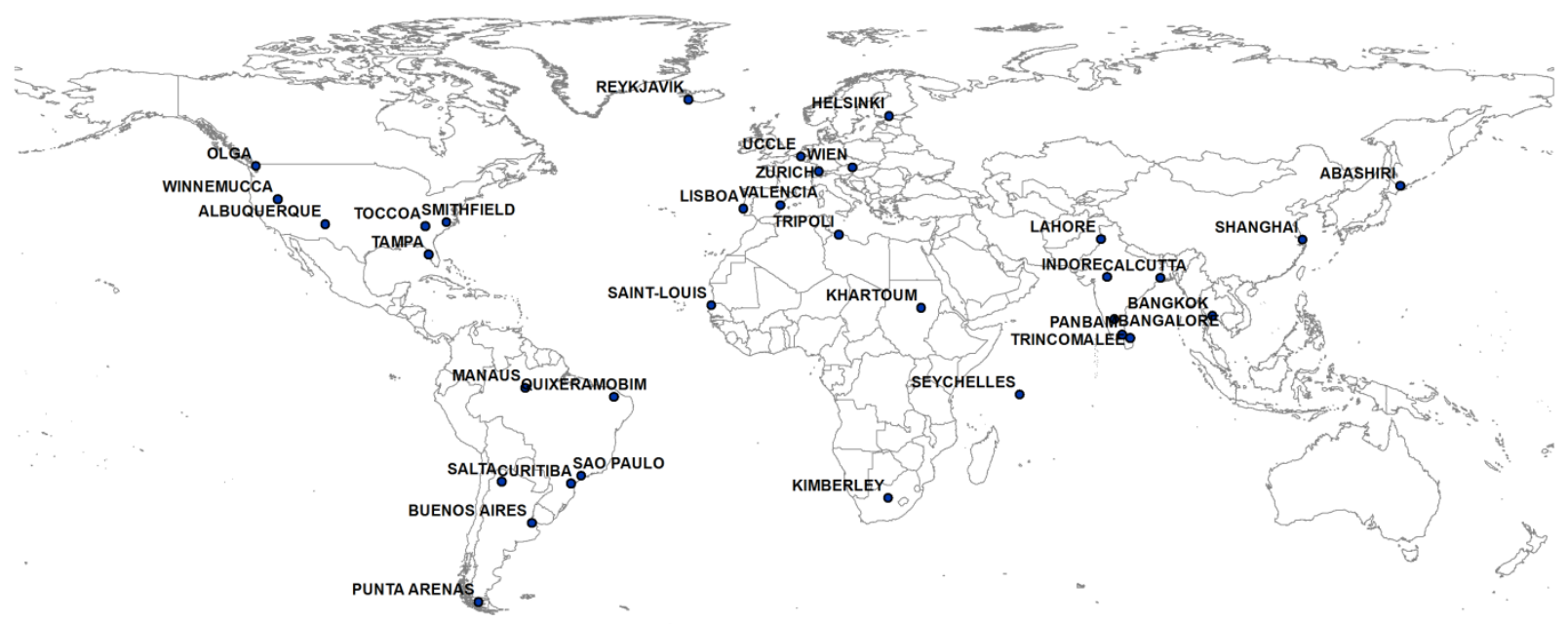


Figure 2. Location of the 34 observatories with 107 years of data of precipitation and mean 729 temperature used.

730 

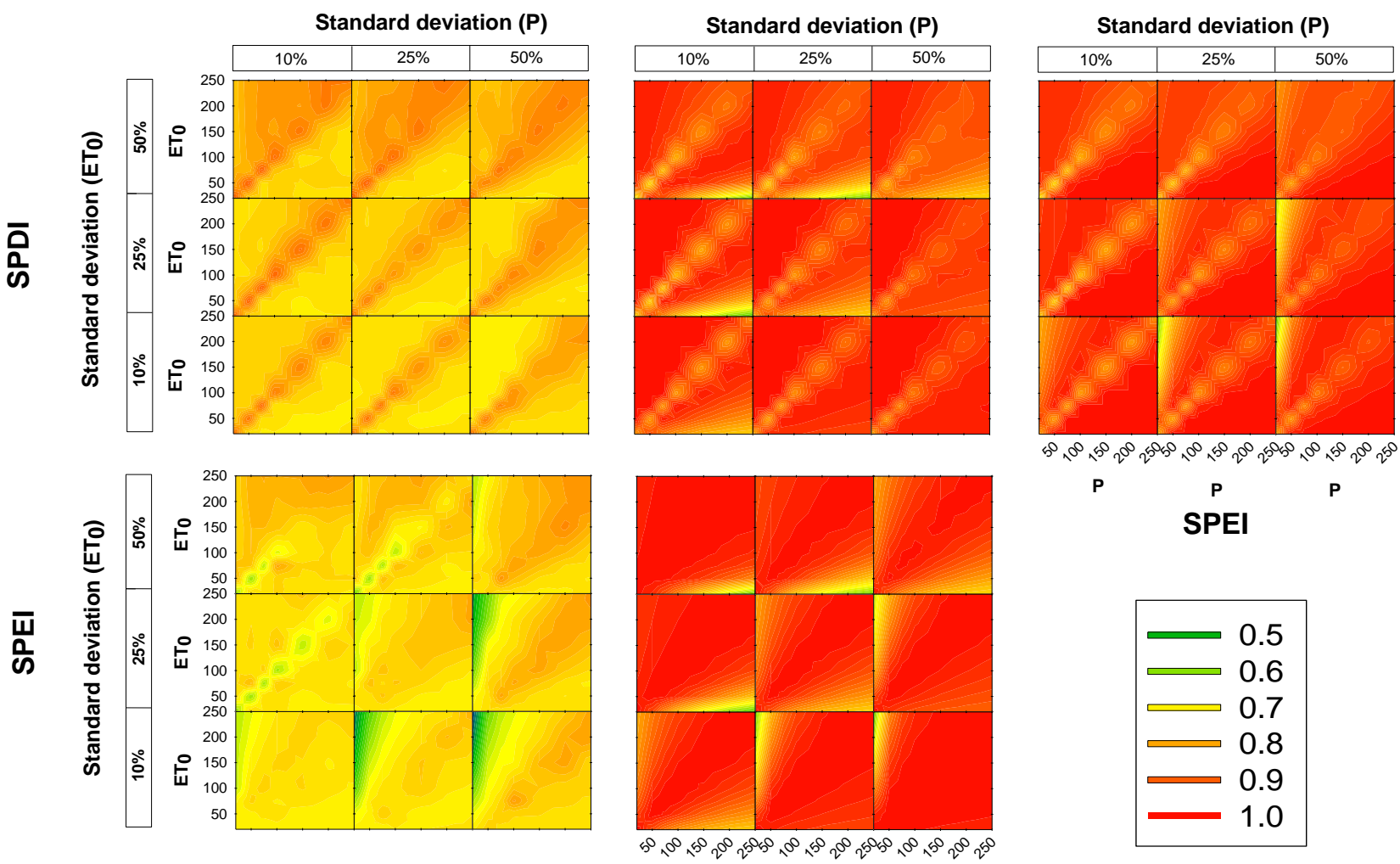

SPEI
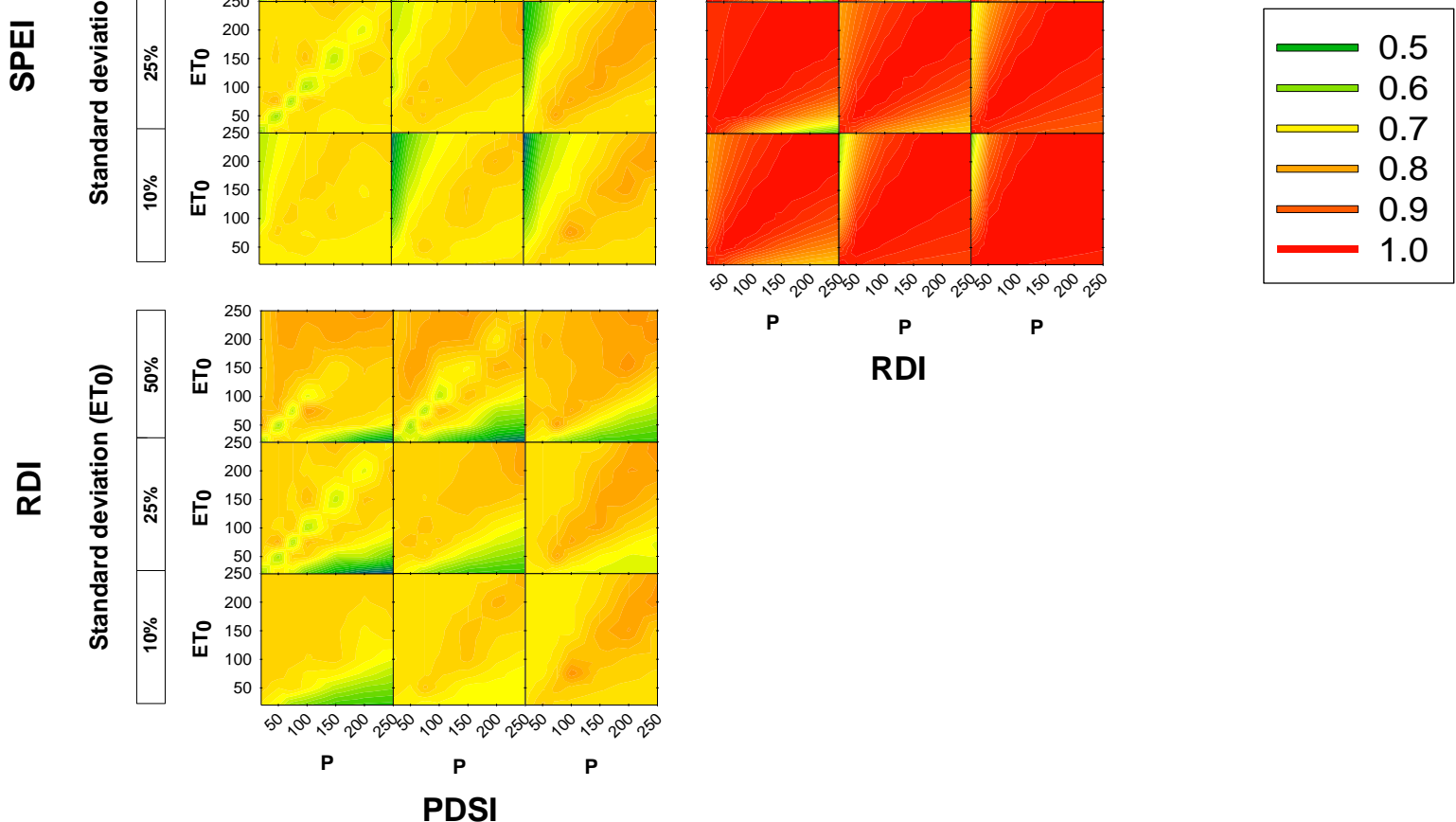

Figure 3. Pearson's r correlations between the time series of the four different drought indices (PDSI, RDI, SPEI and SPDI) based on simulated P and ETo series of 100 years with different averages and standard deviations. PDSI and SPDI are obtained considering a soil water capacity equal to 1000 $\mathrm{mm}$. Each 9x9 matrix relates to a comparison between two drought indices, where each element within each matrix relates to a specified level of standard deviation of ETo and P. Each element consists of 441 simulations where series of P and ETo, with specified means, are combined to calculate drought index series. 


\begin{tabular}{|c|c|c|c|c|c|c|}
\hline OBSERVATORY & PDSI vs. RDI & PDSI vs. SPEI & PDSI vs. SPDI & RDI vs. SPEI & RDI vs.SPDI & SPEI VS. SPDI \\
\hline INDORE & 0.82 & 0.84 & 0.92 & 0.98 & 0.91 & 0.91 \\
\hline KIMBERLEY & 0.76 & 0.79 & 0.82 & 0.96 & 0.97 & 0.96 \\
\hline ALBUQUERQUE & 0.66 & 0.68 & 0.82 & 0.83 & 0.89 & 0.84 \\
\hline VALENCIA & 0.77 & 0.80 & 0.89 & 0.93 & 0.93 & 0.92 \\
\hline WIEN & 0.83 & 0.85 & 0.94 & 1.00 & 0.88 & 0.90 \\
\hline ABASHIRI & 0.82 & 0.81 & 0.81 & 0.99 & 0.91 & 0.92 \\
\hline TAMPA & 0.81 & 0.81 & 0.88 & 1.00 & 0.90 & 0.91 \\
\hline SAO PAULO & 0.74 & 0.70 & 0.76 & 0.97 & 0.92 & 0.94 \\
\hline LAHORE & 0.76 & 0.79 & 0.84 & 0.97 & 0.95 & 0.95 \\
\hline PUNTA_ARENAS & 0.79 & 0.79 & 0.89 & 0.99 & 0.90 & 0.90 \\
\hline HELSINKI & 0.81 & 0.80 & 0.89 & 0.99 & 0.89 & 0.89 \\
\hline TRIPOLI & 0.81 & 0.80 & 0.91 & 0.95 & 0.90 & 0.87 \\
\hline KHARTOUM & 0.71 & 0.53 & 0.80 & 0.83 & 0.95 & 0.75 \\
\hline LISBOA & 0.79 & 0.80 & 0.92 & 0.99 & 0.89 & 0.89 \\
\hline QUIXERAMOBIM & 0.83 & 0.84 & 0.93 & 0.97 & 0.94 & 0.93 \\
\hline ZURICH & 0.76 & 0.76 & 0.77 & 0.98 & 0.95 & 0.96 \\
\hline UCCLE & 0.78 & 0.78 & 0.80 & 0.99 & 0.89 & 0.90 \\
\hline CURITIBA & 0.77 & 0.77 & 0.77 & 0.98 & 0.96 & 0.97 \\
\hline REYKJAVIK & 0.80 & 0.81 & 0.84 & 0.99 & 0.91 & 0.92 \\
\hline TOCCOA & 0.76 & 0.75 & 0.76 & 0.99 & 0.95 & 0.95 \\
\hline CALCUTTA & 0.70 & 0.70 & 0.78 & 1.00 & 0.92 & 0.92 \\
\hline WINNEMUCCA & 0.63 & 0.68 & 0.84 & 0.94 & 0.86 & 0.88 \\
\hline SHANGHAI & 0.76 & 0.76 & 0.80 & 1.00 & 0.92 & 0.92 \\
\hline SAINT-LOUIS & 0.78 & 0.68 & 0.87 & 0.93 & 0.96 & 0.85 \\
\hline BANGKOK & 0.81 & 0.81 & 0.88 & 1.00 & 0.90 & 0.89 \\
\hline TRINCOMALEE & 0.74 & 0.74 & 0.78 & 1.00 & 0.91 & 0.91 \\
\hline PANBAM & 0.71 & 0.72 & 0.84 & 0.99 & 0.91 & 0.90 \\
\hline BANGALORE & 0.76 & 0.75 & 0.84 & 1.00 & 0.88 & 0.88 \\
\hline SEYCHELLES & 0.74 & 0.74 & 0.79 & 0.99 & 0.95 & 0.95 \\
\hline SALTA & 0.72 & 0.72 & 0.91 & 1.00 & 0.87 & 0.87 \\
\hline BUENOS AIRES & 0.82 & 0.82 & 0.85 & 1.00 & 0.92 & 0.92 \\
\hline SMITHFIELD & 0.73 & 0.73 & 0.76 & 1.00 & 0.93 & 0.93 \\
\hline OLGA & 0.78 & 0.78 & 0.84 & 1.00 & 0.92 & 0.92 \\
\hline MANAUS & 0.85 & 0.85 & 0.85 & 1.00 & 0.96 & 0.96 \\
\hline
\end{tabular}

Table 1. Pearson's r correlations between the different drought indices in the thirty-four observatories with 107 years of P and ETo. 

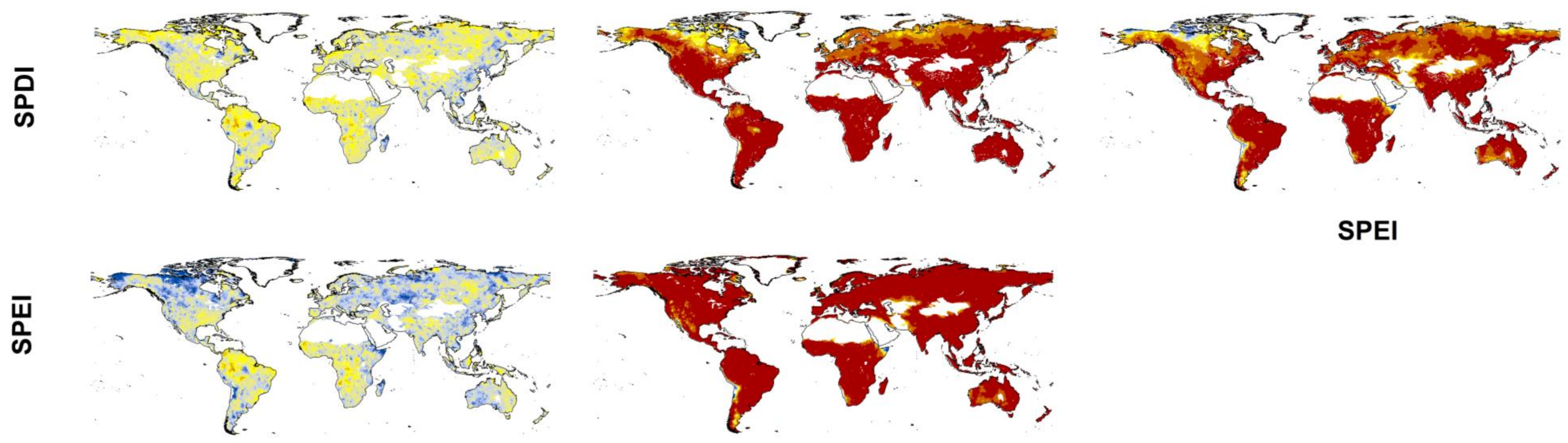

SPEI
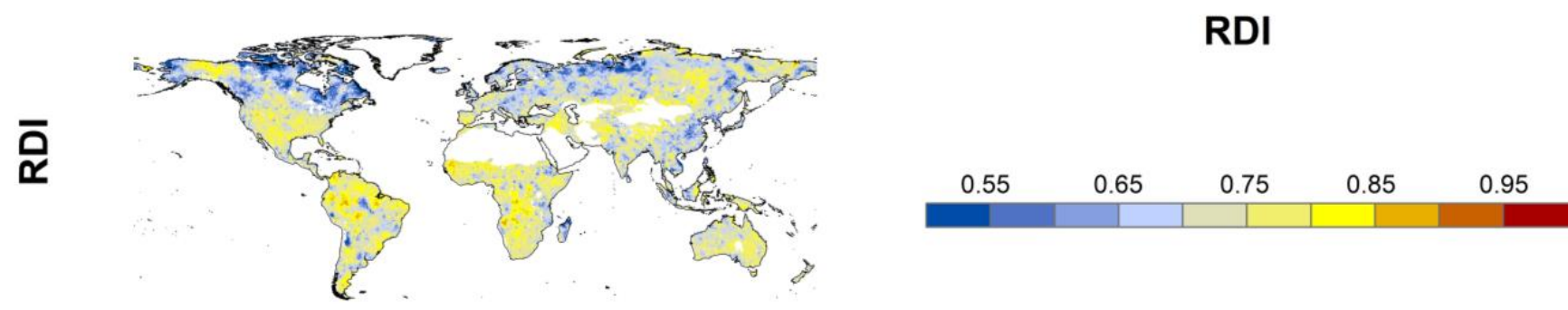

\section{PDSI}

Figure 4. Pearson's $r$ correlations between the four drought indices at the global scale from gridded datasets. 
Precipitation

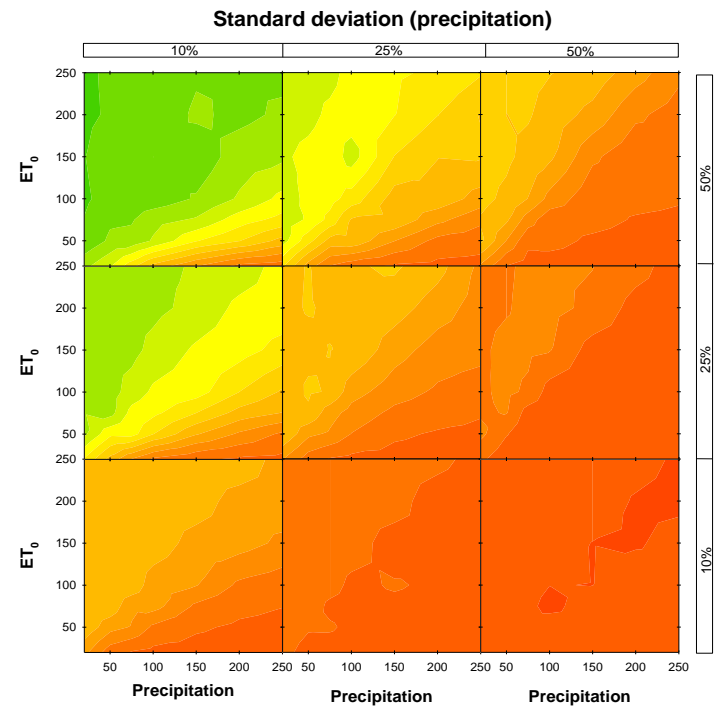

$\mathrm{ET}_{0}$

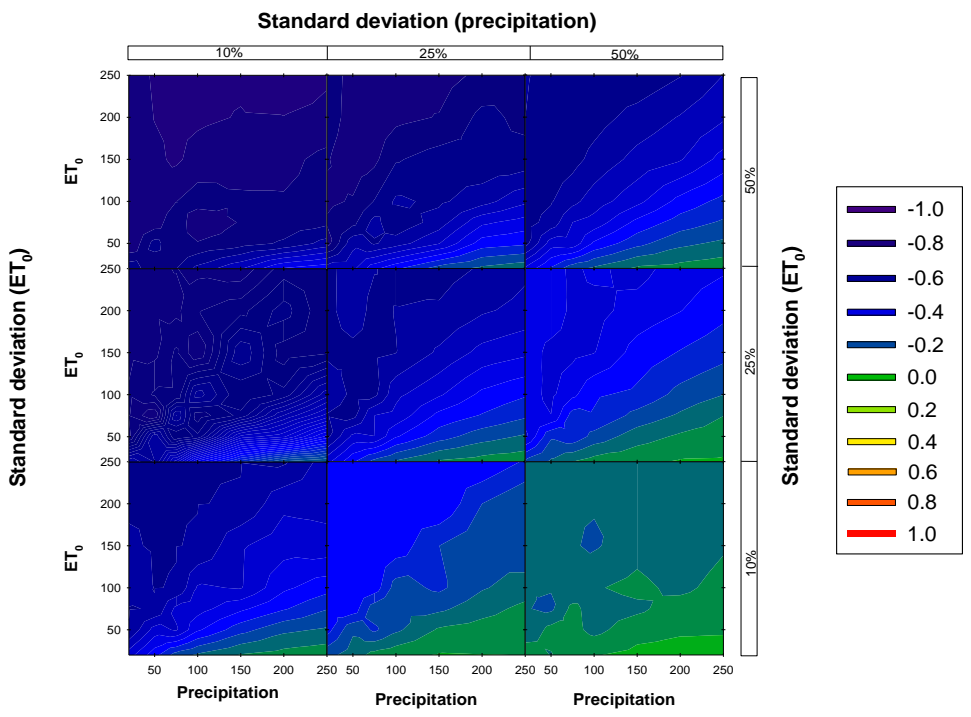

Figure 5. Pearson's r correlation coefficients between best correlated 1-24-month time-scale $\mathrm{P}$ and best correlated 1-24-month time-scale ETo and PDSI from simulated series. Soil water capacity = $1000 \mathrm{~mm}$. 
Precipitation

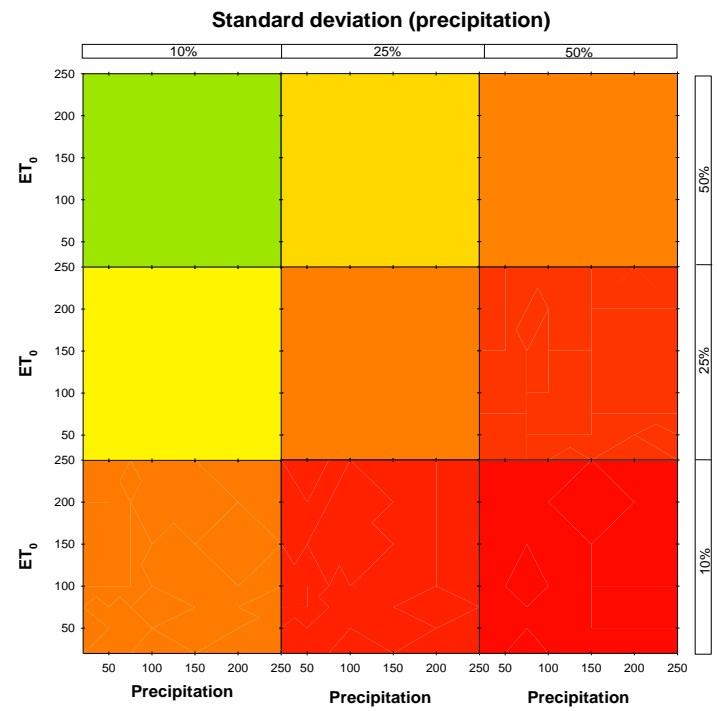

$\mathrm{ET}_{0}$

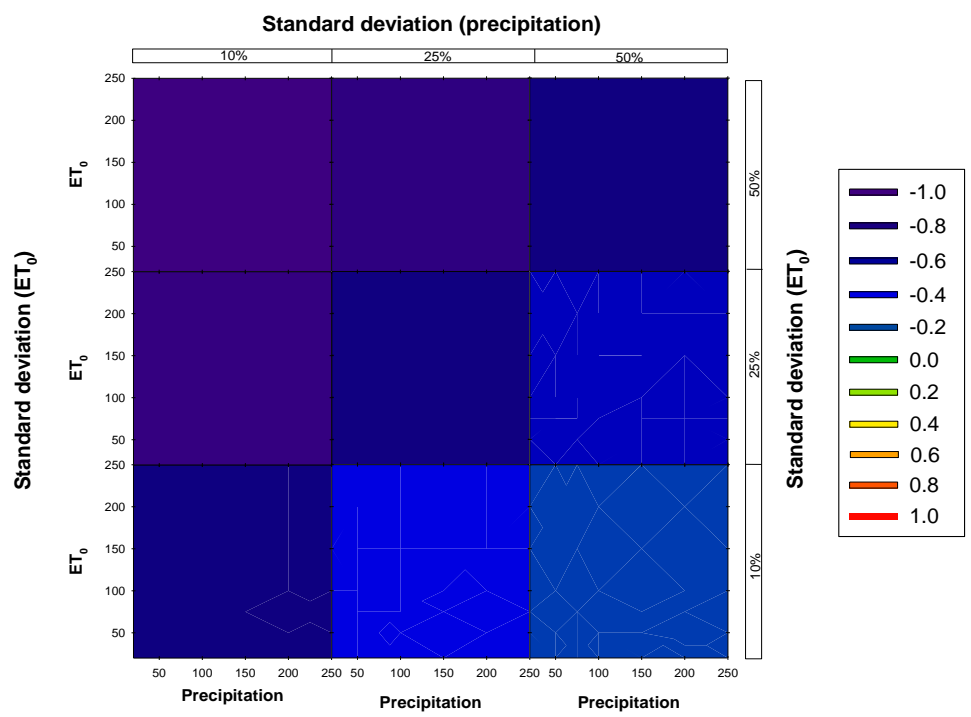

Figure 6. Pearson's r correlation coefficients between 12-month P and 12- month ETo and the RDI from simulated series. 
Precipitation

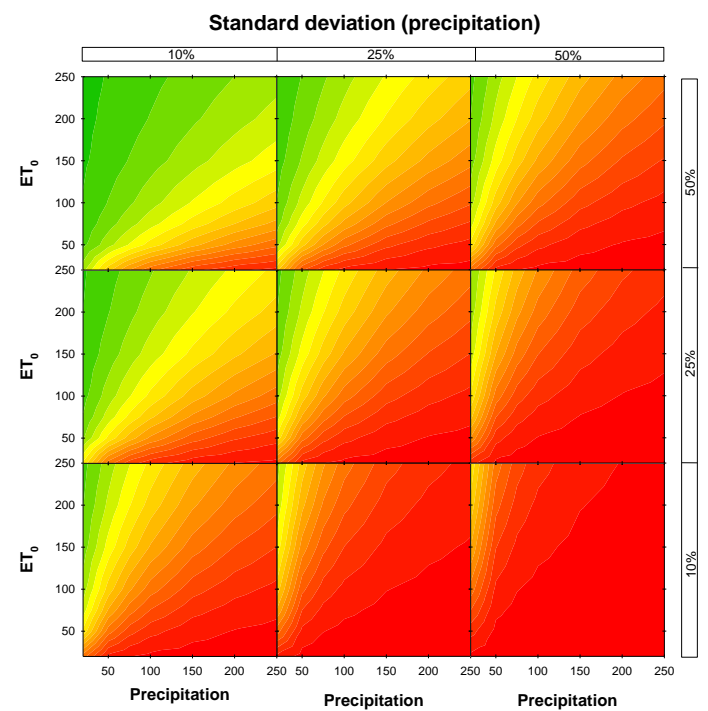

$\mathrm{ET}_{0}$

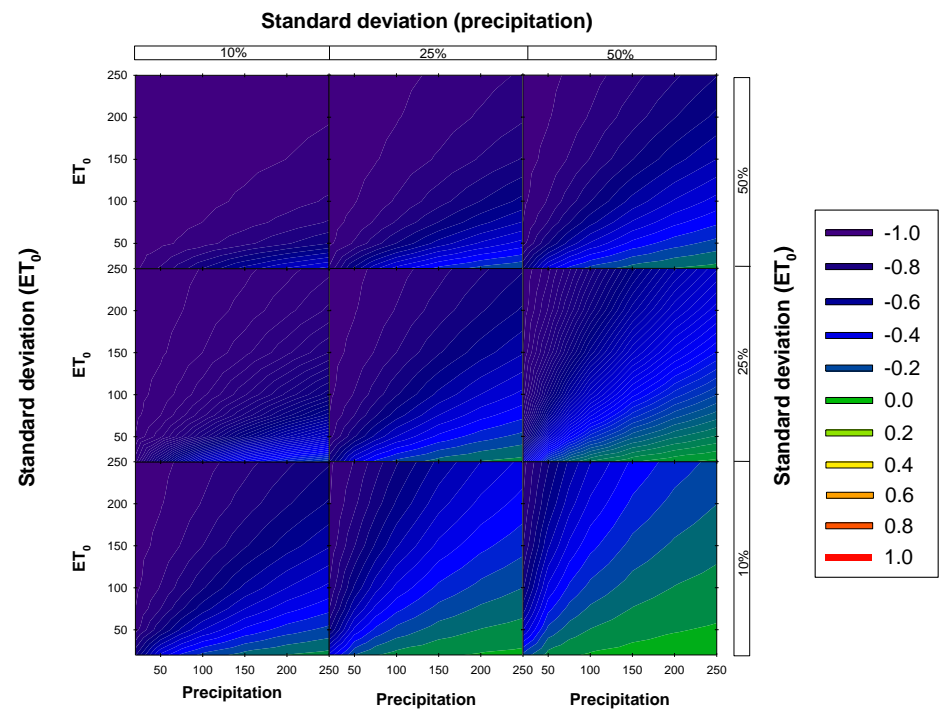

Figure 7. Pearson's r correlation coefficients between 12-month P and 12- month ETo and the SPEI from simulated series. 
Precipitation

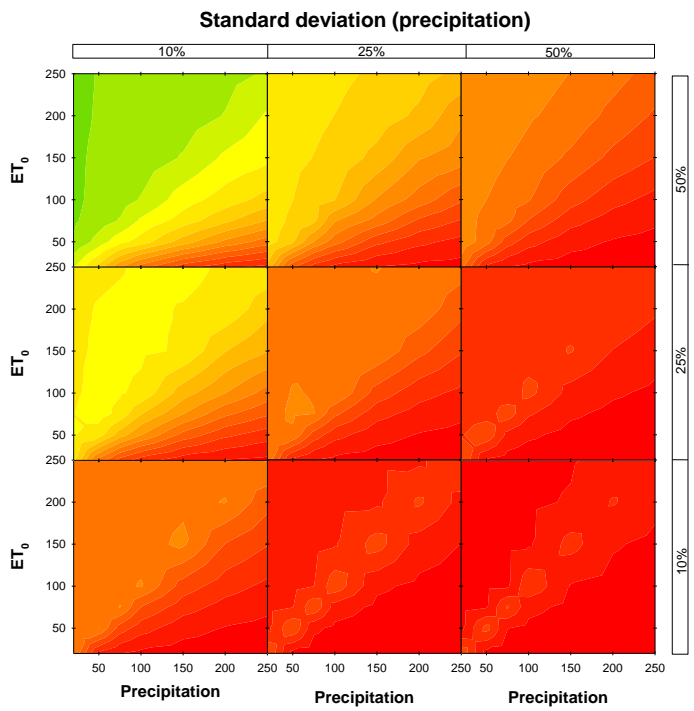

$\mathrm{ET}_{0}$

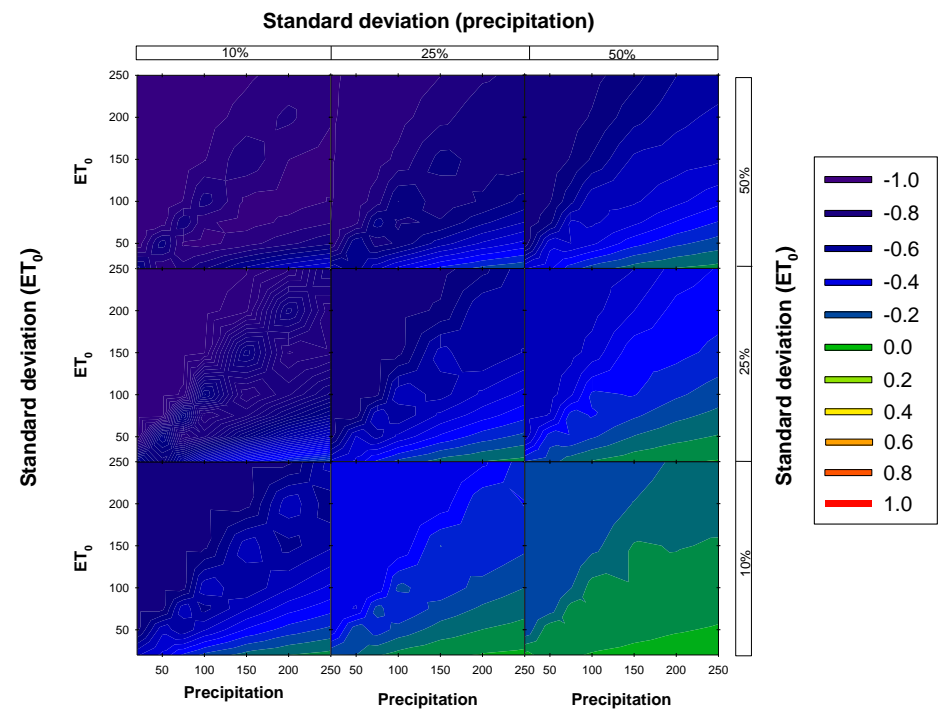

Figure 8. Pearson's r correlation coefficients between 12-month P and 12- month ETo and the SPDI from simulated series. Soil water capacity $=1000 \mathrm{~mm}$. 


\section{PRECIPITATION}

PDSI

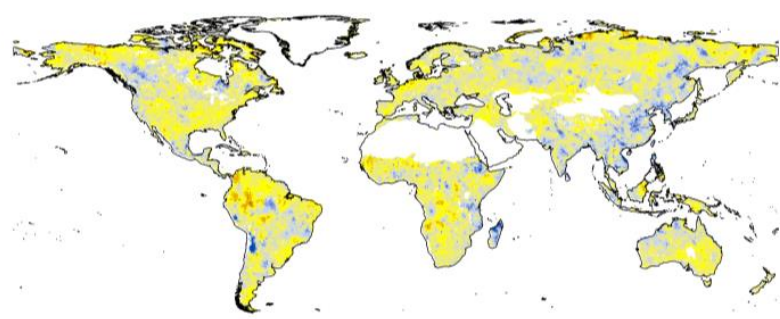

RDI

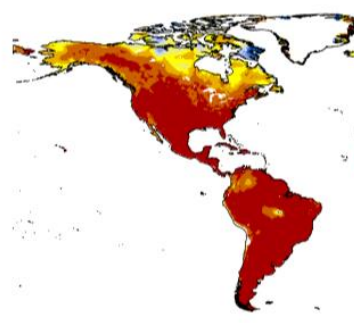

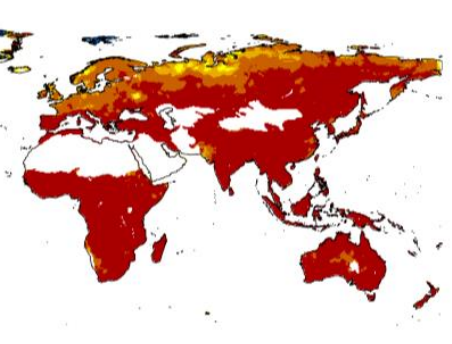

SPEI

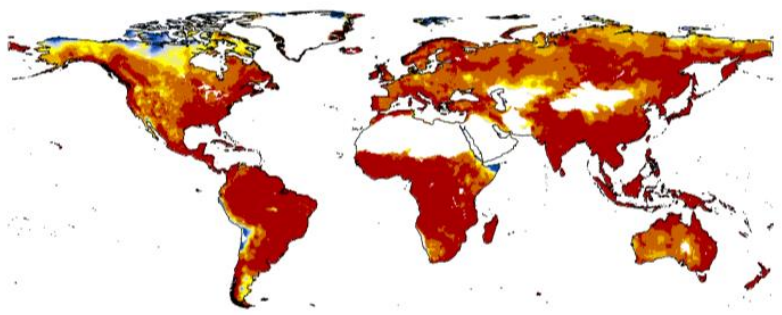

SPDI

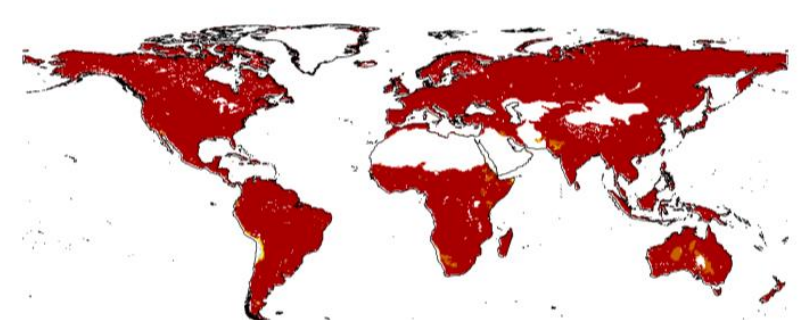

$\begin{array}{lllll}0.55 & 0.65 & 0.75 & 0.85 & 0.95\end{array}$

\section{REFERENCE EVAPOTRANSPIRATION}

PDSI

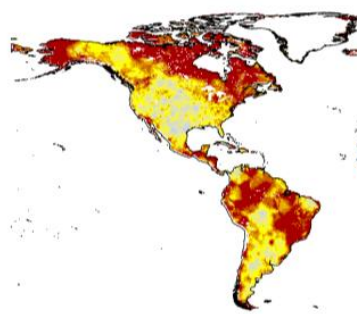

RDI

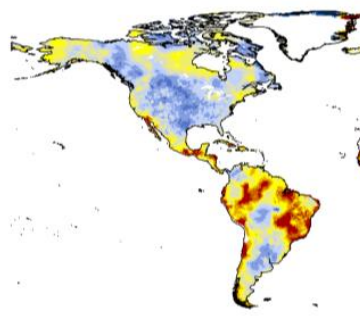

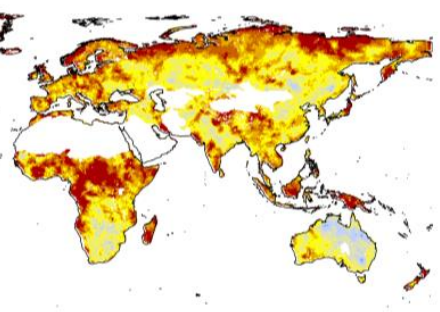

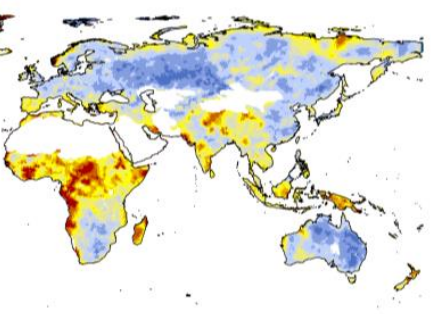

SPEI

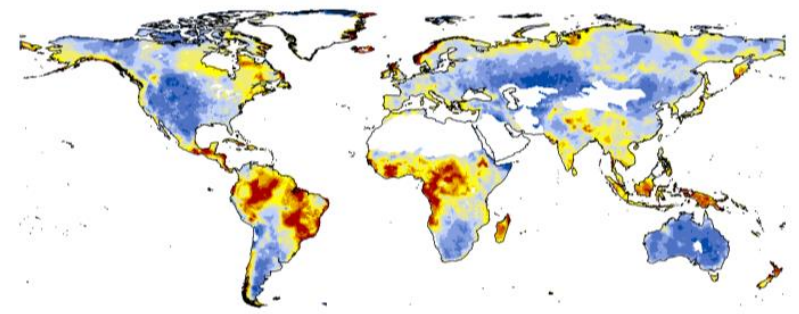

SPDI

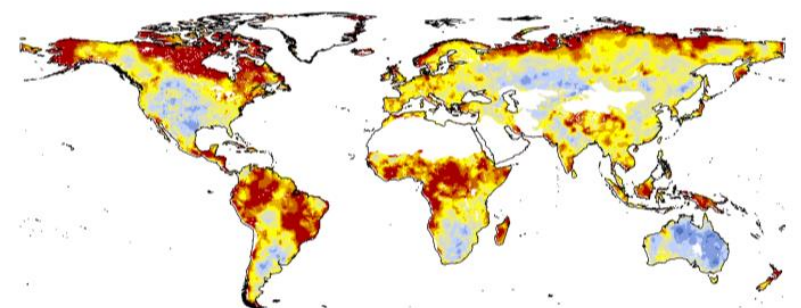

$\begin{array}{lllll}-0.90 & -0.70 & -0.50 & -0.30 & -0.1\end{array}$

Figure 9. Pearson's r correlation between the gridded series of the PDSI, the RDI, the SPEI and the SPDI and the best correlated 1-24-month time-scale P and best correlated 1-24-month time-scale ETo for the PDSI and 12-month P and 12- month ETo for the rest of indices. 


\begin{tabular}{|c|c|c|c|c|c|c|c|c|c|}
\hline & & PDSI vs. $P$ & PDSI vs. ETo & RDI vs. P & RDI vs. ETo & SPEI vs. P & SPEI vs. ETo & SPDI vs. P & SPDI vs. ETo \\
\hline \multirow{4}{*}{ 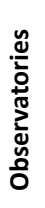 } & Avg. $\mathrm{P}$ & 0.08 & 0.13 & 0.00 & 0.04 & 0.38 & 0.49 & 0.18 & 0.14 \\
\hline & Desv. P & 0.14 & 0.20 & 0.01 & 0.16 & 0.29 & 0.46 & 0.25 & 0.23 \\
\hline & Avg. ETo & 0.10 & 0.28 & 0.18 & 0.35 & 0.02 & 0.06 & 0.22 & 0.27 \\
\hline & Desv. ETo & 0.10 & 0.12 & 0.23 & 0.03 & 0.29 & 0.10 & 0.12 & 0.05 \\
\hline \multirow{4}{*}{ 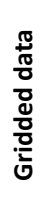 } & Avg. P & 0.00 & 0.03 & 0.06 & 0.13 & 0.22 & 0.37 & 0.00 & 0.05 \\
\hline & Desv. P & 0.00 & 0.00 & 0.11 & 0.12 & 0.23 & 0.25 & 0.00 & 0.01 \\
\hline & Avg. ETo & 0.00 & 0.12 & 0.23 & 0.05 & 0.05 & 0.00 & 0.00 & 0.10 \\
\hline & Desv. ETo & 0.08 & 0.13 & 0.00 & 0.04 & 0.38 & 0.49 & 0.18 & 0.14 \\
\hline
\end{tabular}

Table 2. Linear $\mathrm{R}^{2}$ coefficients between the four drought indices and $\mathrm{P}$ and ETo in each one of the 34 observatories and the gridded datasets and the average and standard deviation of $\mathrm{P}$ and ETo. 


\section{OBSERVATORIES}
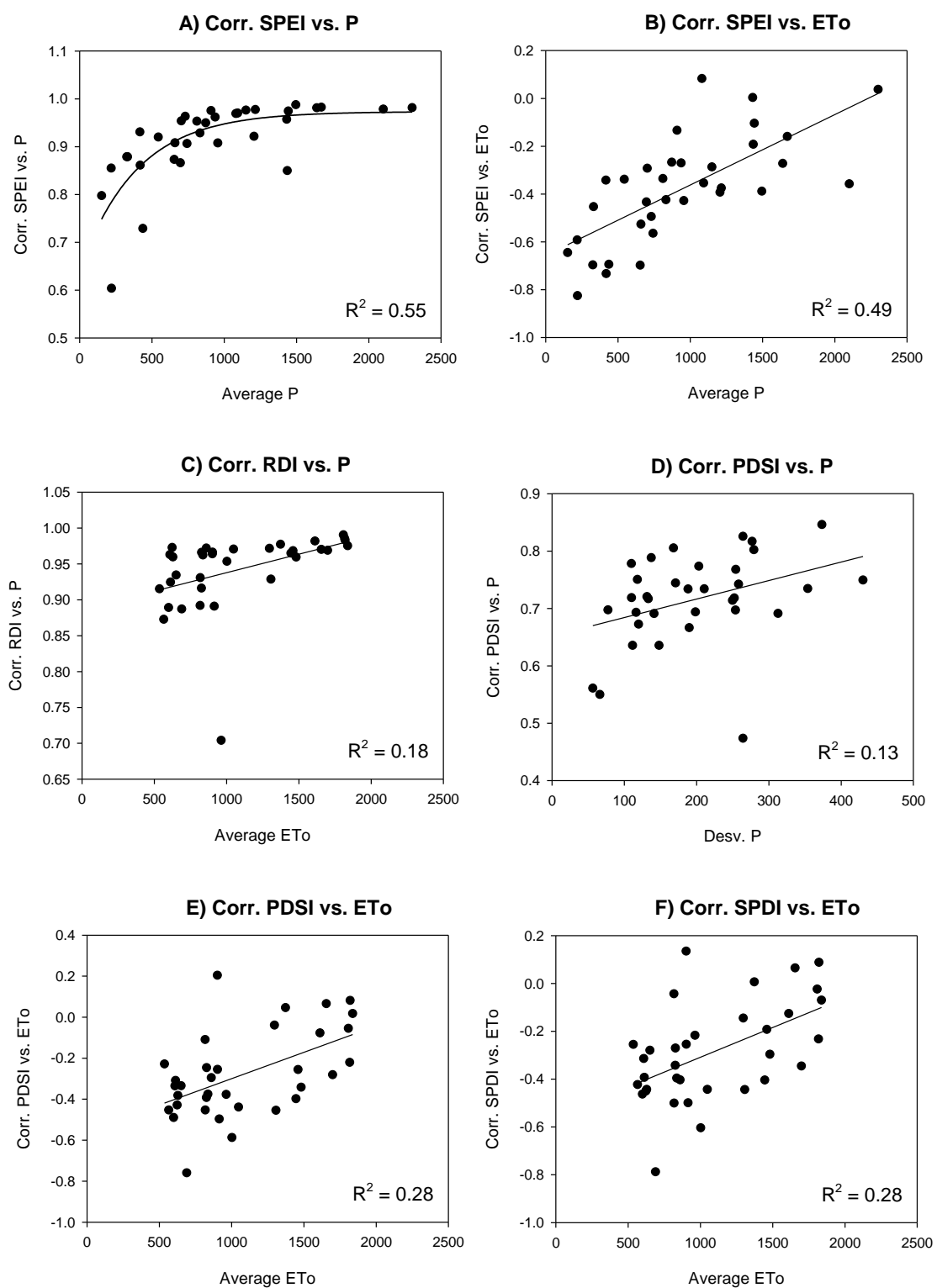

\section{GRIDDED DATA}
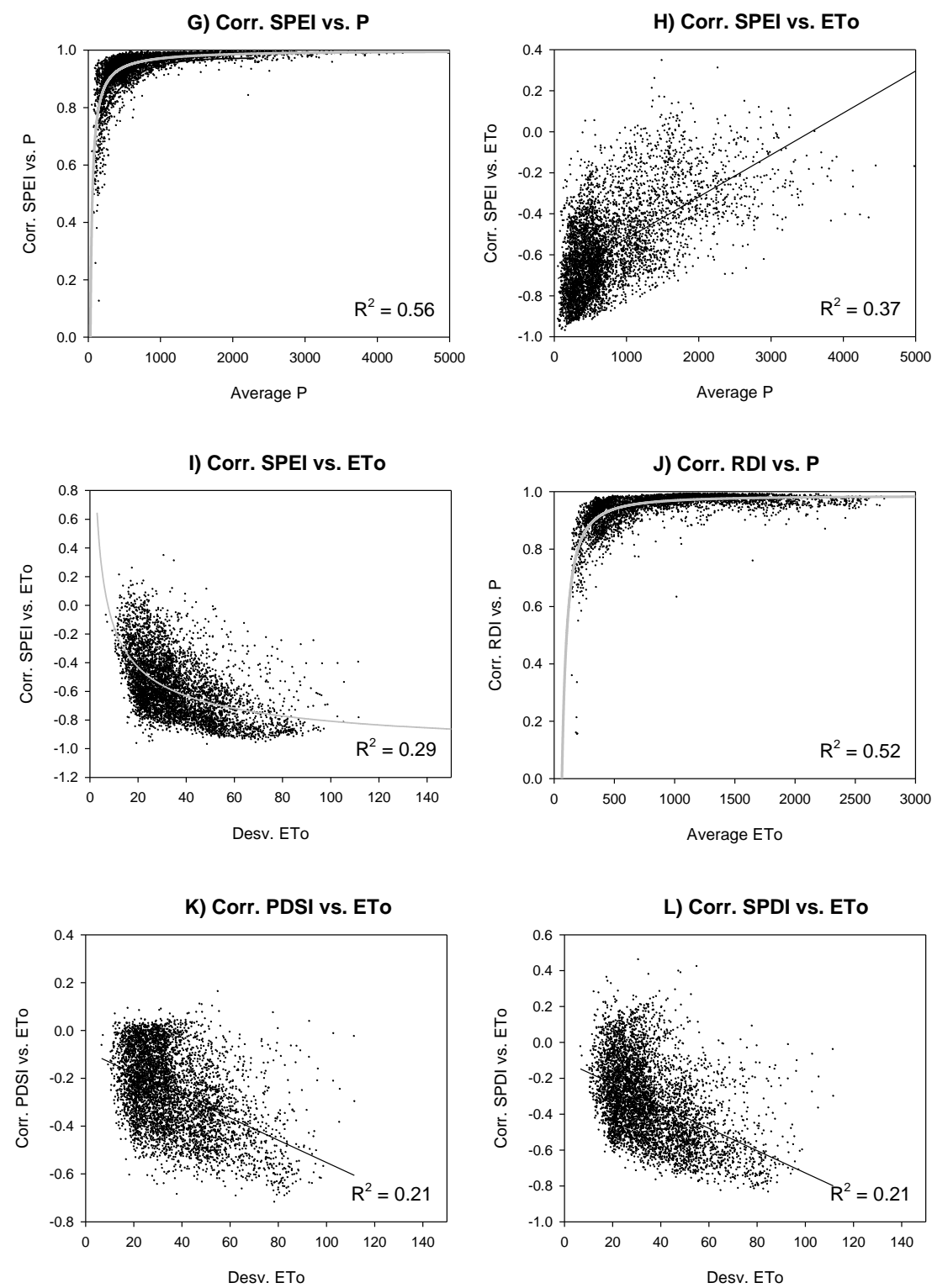
Figure 10. Selected patterns of relationship between the average and standard deviation P and ETo recorded in the different meteorological observatories and gridded series and the temporal Pearson's $\mathrm{r}$ correlations between the drought indices and P and ETo series. 


\section{Supplementary material}

\section{Contribution of precipitation and reference evapotranspiration to drought}

indices under different climates

Sergio M. Vicente-Serrano ${ }^{1,{ }^{*}}$, Gerard Van der Schrier $^{2}$, Santiago Beguería ${ }^{3}$, Cesar Azorin-Molina ${ }^{1}$, Juan-I. Lopez-Moreno ${ }^{1}$

${ }^{1}$ Instituto Pirenaico de Ecología, Consejo Superior de Investigaciones Científicas (IPE-CSIC), Spain, ${ }^{2}$ Royal Netherlands Meteorological Institute (KNMI), 3730 AE De Bilt, Netherlands. ${ }^{3}$ Estación Experimental de Aula Dei (EEAD-CSIC), Zaragoza,

* Corresponding author: svicen@ipe.csic.es

This document contains Supplementary tables and figures. 


\begin{tabular}{|c|c|c|c|c|c|c|c|c|c|c|c|c|}
\hline OBSERVATORY & Avg. P & Desv. $\mathrm{P}$ & Avg. ETo & Desv. Eto & $\begin{array}{l}\text { PDSI vs. } \\
\mathrm{P}\end{array}$ & $\begin{array}{l}\text { PDSI vs. } \\
\text { ETo }\end{array}$ & $\begin{array}{l}\text { RDI } \\
\text { vs. P }\end{array}$ & $\begin{array}{l}\text { RDI vs. } \\
\text { ETo }\end{array}$ & \begin{tabular}{|l} 
SPEI vs. \\
$\mathrm{P}$
\end{tabular} & $\begin{array}{l}\text { SPEl vs. } \\
\text { ETo } \\
\end{array}$ & SPDI vs. P & \begin{tabular}{|l|} 
SPDI vs. \\
ETo \\
\end{tabular} \\
\hline INDORE & 954.8 & 254.1 & 1481.1 & 108.4 & 0.77 & -0.34 & 0.96 & -0.27 & 0.91 & -0.43 & 0.87 & -0.3 \\
\hline KIMBERLEY & 417.9 & 119.8 & 1001.8 & 87.1 & 0.67 & -0.59 & 0.95 & -0.54 & 0.86 & -0.73 & 0.9 & -0.6 \\
\hline ALBUQUERQUE & 219.1 & 66.1 & 817.4 & 91.6 & 0.55 & -0.45 & 0.93 & -0.38 & 0.6 & -0.82 & 0.78 & -0.5 \\
\hline VALENCIA & 436.7 & 148.1 & 914.3 & 134.1 & 0.64 & -0.5 & 0.89 & -0.41 & 0.73 & -0.69 & 0.79 & -0.5 \\
\hline WIEN & 653.7 & 111.3 & 689.3 & 72.3 & 0.64 & -0.76 & 0.89 & -0.67 & 0.87 & -0.7 & 0.69 & -0.79 \\
\hline ABASHIRI & 832.2 & 133.1 & 564.8 & 50.7 & 0.72 & -0.45 & 0.87 & -0.54 & 0.93 & -0.42 & 0.85 & -0.42 \\
\hline TAMPA & 1206.2 & 253.7 & 1307 & 97.6 & 0.7 & -0.46 & 0.93 & -0.37 & 0.92 & -0.39 & 0.81 & -0.44 \\
\hline SAO PAULO & 1435.9 & 264.2 & 962.1 & 138.4 & 0.47 & -0.38 & 0.7 & -0.41 & 0.85 & -0.19 & 0.78 & -0.22 \\
\hline LAHORE & 543.7 & 188.2 & 1459.8 & 70.3 & 0.73 & -0.26 & 0.97 & -0.12 & 0.92 & -0.34 & 0.92 & -0.19 \\
\hline PUNTA ARENAS & 416.5 & 109.9 & 607.4 & 39.8 & 0.72 & -0.34 & 0.96 & -0.23 & 0.93 & -0.34 & 0.84 & -0.31 \\
\hline HELSINKI & 658.7 & 116.2 & 598.4 & 57 & 0.69 & -0.49 & 0.89 & -0.56 & 0.91 & -0.53 & 0.81 & -0.46 \\
\hline TRIPOLI & 325.2 & 109.7 & 1048.1 & 68.1 & 0.78 & -0.44 & 0.97 & -0.45 & 0.88 & -0.7 & 0.87 & -0.44 \\
\hline KHARTOUM & 151 & 77.3 & 1837.4 & 55.6 & 0.7 & 0.02 & 0.98 & -0.13 & 0.8 & -0.64 & 0.91 & -0.07 \\
\hline LISBOA & 696.6 & 189.8 & 825.2 & 111.2 & 0.67 & -0.39 & 0.92 & -0.32 & 0.87 & -0.43 & 0.8 & -0.34 \\
\hline QUIXERAMOBIM & 742.2 & 279.2 & 1445.4 & 136.8 & 0.8 & -0.4 & 0.97 & -0.39 & 0.91 & -0.56 & 0.9 & -0.4 \\
\hline ZURICH & 1092.9 & 170.9 & 611.7 & 41.9 & 0.74 & -0.31 & 0.92 & -0.49 & 0.97 & -0.35 & 0.92 & -0.39 \\
\hline UCCLE & 810.7 & 131.4 & 650.6 & 41.1 & 0.72 & -0.34 & 0.93 & -0.4 & 0.95 & -0.34 & 0.86 & -0.28 \\
\hline CURITIBA & 1431.9 & 249.8 & 816.6 & 61.9 & 0.71 & -0.11 & 0.89 & -0.18 & 0.96 & 0 & 0.93 & -0.04 \\
\hline REYKJAVIK & 871.6 & 168 & 535.1 & 39.9 & 0.81 & -0.23 & 0.92 & -0.37 & 0.95 & -0.27 & 0.88 & -0.26 \\
\hline TOCCOA & 1495.1 & 258 & 859.3 & 38 & 0.74 & -0.3 & 0.97 & -0.47 & 0.99 & -0.39 & 0.94 & -0.4 \\
\hline CALCUTTA & 1670.8 & 312.6 & 1610.7 & 45.3 & 0.69 & -0.08 & 0.98 & -0.17 & 0.98 & -0.16 & 0.92 & -0.13 \\
\hline WINNEMUCCA & 217.2 & 56.3 & 623 & 34.9 & 0.56 & -0.43 & 0.97 & -0.29 & 0.86 & -0.59 & 0.8 & -0.45 \\
\hline SHANGHAI & 1149.4 & 210.6 & 901.9 & 43.4 & 0.73 & -0.26 & 0.97 & -0.33 & 0.98 & -0.29 & 0.91 & -0.26 \\
\hline SAINT-LOUIS & 330.4 & 137.2 & 1372.7 & 66.2 & 0.79 & 0.05 & 0.98 & -0.1 & 0.88 & -0.45 & 0.94 & 0.01 \\
\hline BANGKOK & 1443.3 & 276.8 & 1820.2 & 53.6 & 0.82 & 0.08 & 0.98 & -0.05 & 0.97 & -0.1 & 0.91 & 0.09 \\
\hline TRINCOMALEE & 1639.4 & 353.8 & 1816.8 & 39.4 & 0.73 & -0.22 & 0.99 & -0.25 & 0.98 & -0.27 & 0.91 & -0.23 \\
\hline PANBAM & 908 & 252.1 & 1807.3 & 47 & 0.72 & -0.06 & 0.99 & -0.03 & 0.98 & -0.13 & 0.9 & -0.02 \\
\hline BANGALORE & 936.5 & 203.1 & 1296.4 & 48.5 & 0.77 & -0.04 & 0.97 & -0.22 & 0.96 & -0.27 & 0.88 & -0.15 \\
\hline SEYCHELLES & 2299.6 & 430.2 & 1654.7 & 70.9 & 0.75 & 0.07 & 0.97 & -0.02 & 0.98 & 0.04 & 0.95 & 0.06 \\
\hline SALTA & 702.1 & 141.2 & 827.1 & 41.9 & 0.69 & -0.25 & 0.97 & -0.25 & 0.95 & -0.29 & 0.83 & -0.27 \\
\hline BUENOS AIRES & 1080.1 & 264.1 & 900.8 & 42 & 0.83 & 0.2 & 0.96 & 0.06 & 0.97 & 0.08 & 0.92 & 0.13 \\
\hline SMITHFIELD & 1215.1 & 198.4 & 836 & 39 & 0.69 & -0.38 & 0.96 & -0.44 & 0.98 & -0.37 & 0.9 & -0.4 \\
\hline OLGA & 730.3 & 118.1 & 628.2 & 33.8 & 0.75 & -0.38 & 0.96 & -0.51 & 0.96 & -0.49 & 0.89 & -0.44 \\
\hline MANAUS & 2100.5 & 373.3 & 1698.9 & 76.1 & 0.85 & -0.28 & 0.97 & -0.41 & 0.98 & -0.36 & 0.94 & -0.35 \\
\hline
\end{tabular}

Supplementary Table 1. Average and standard deviation of 12-month P and ETo in thirty-four observatories with 107 years of P and ETo; Correlation between the PDSI and best correlated 1-24month time-scale $\mathrm{P}$ and best correlated 1-24-month time-scale time-scale ETo; Correlation between the RDI, the SPEI and the SPDI with 12-month P and 12- month ETo. 

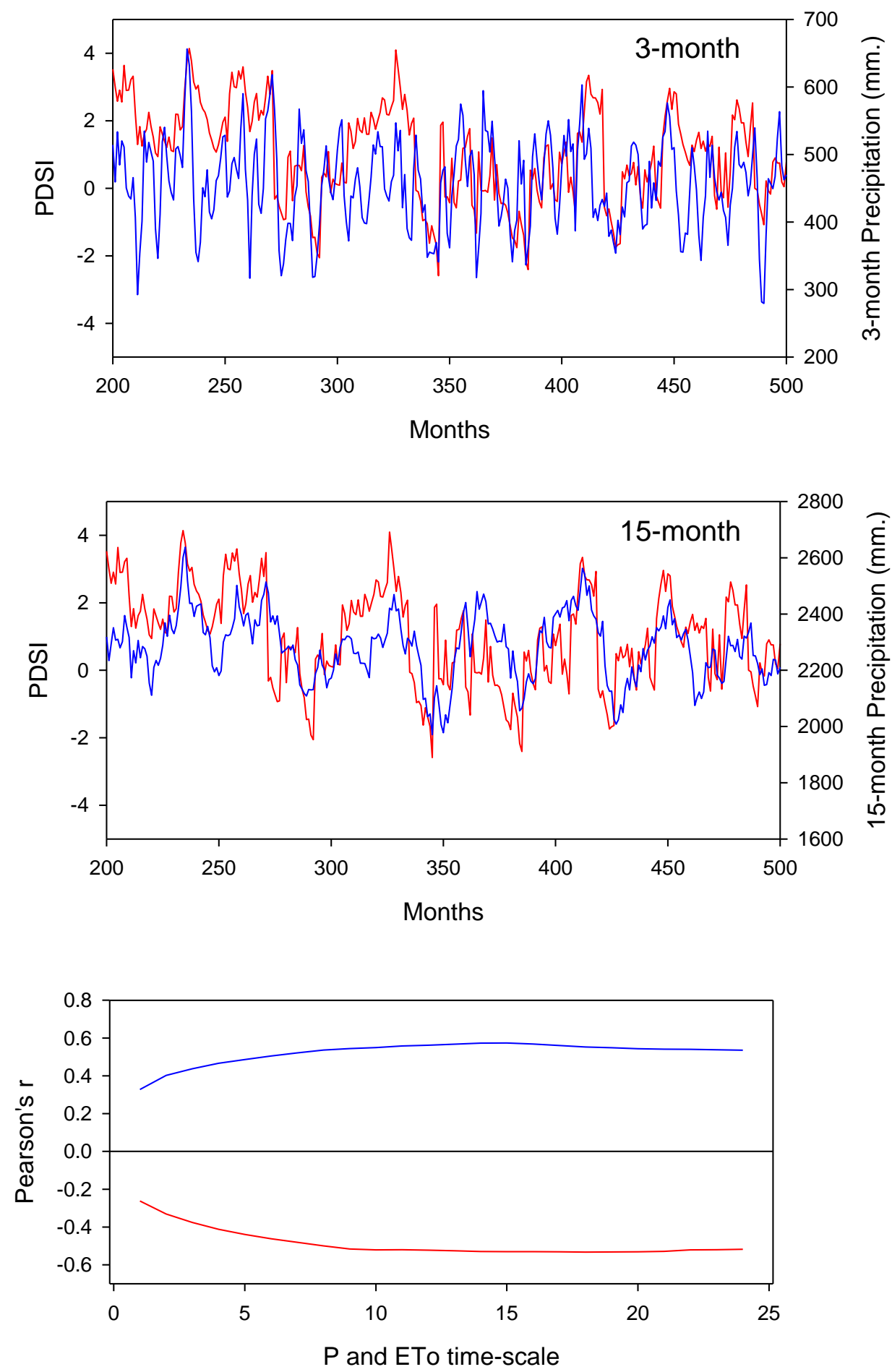

Supplementary Figure 1. Example of the analysis used to select the best $P$ and ETo time-scales to represent sc-PDSI variability. The presented PDSI series (red) is related to P series (blue) at 3- and 15-month timescales. The bottom panel shows the Pearson correlation coefficients calculated between the PDSI and the P (blue) and ETo (red) series on time-scales between 1- and 24-months. In this case maximum positive correlation between PDSI and $P$ is recorded at 15-month time-scale $(r=0.57)$ and negative correlation between PDSI and ETo is found at 18-month time-scale $(r=-0.53)$. 

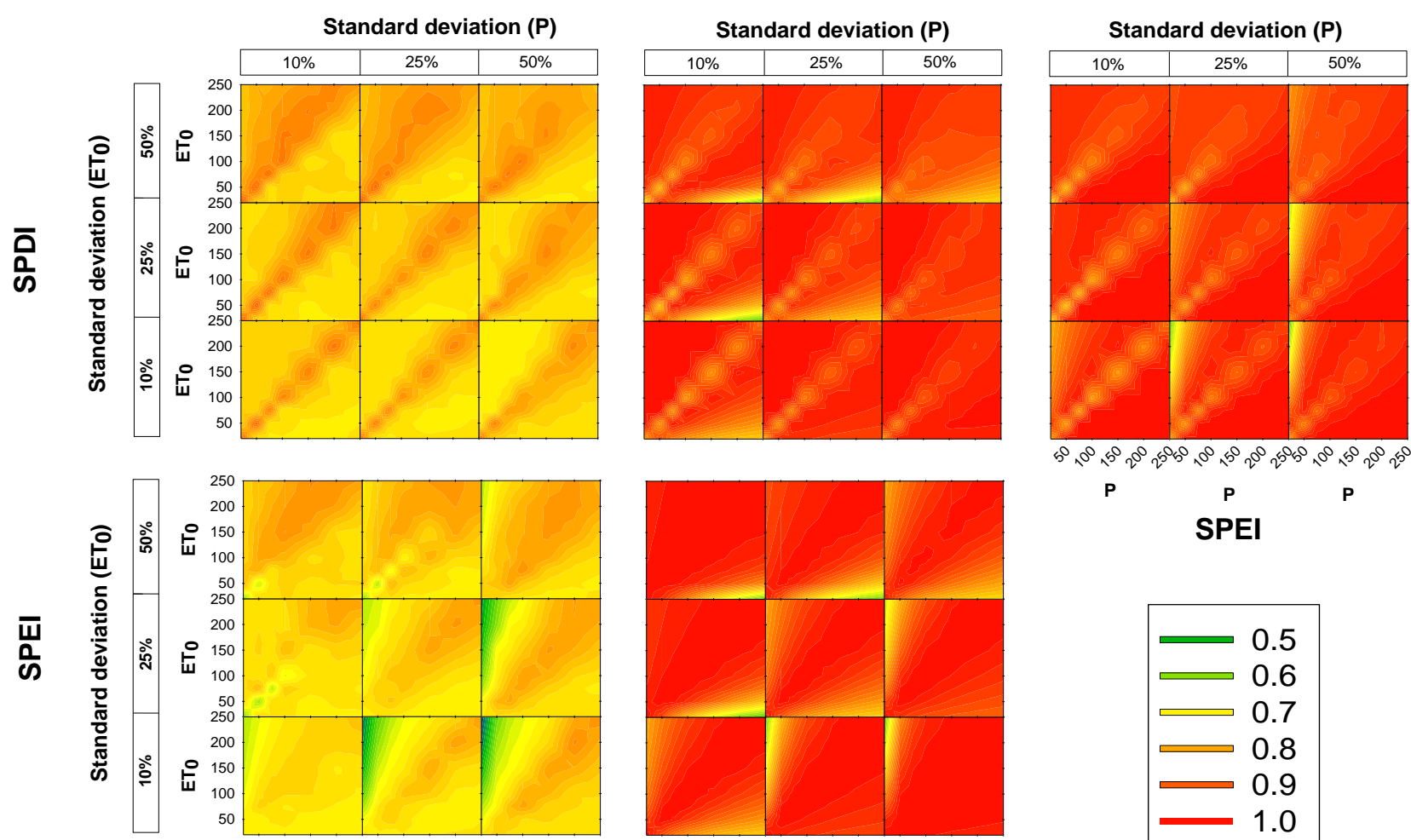

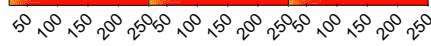

$P$

SPE
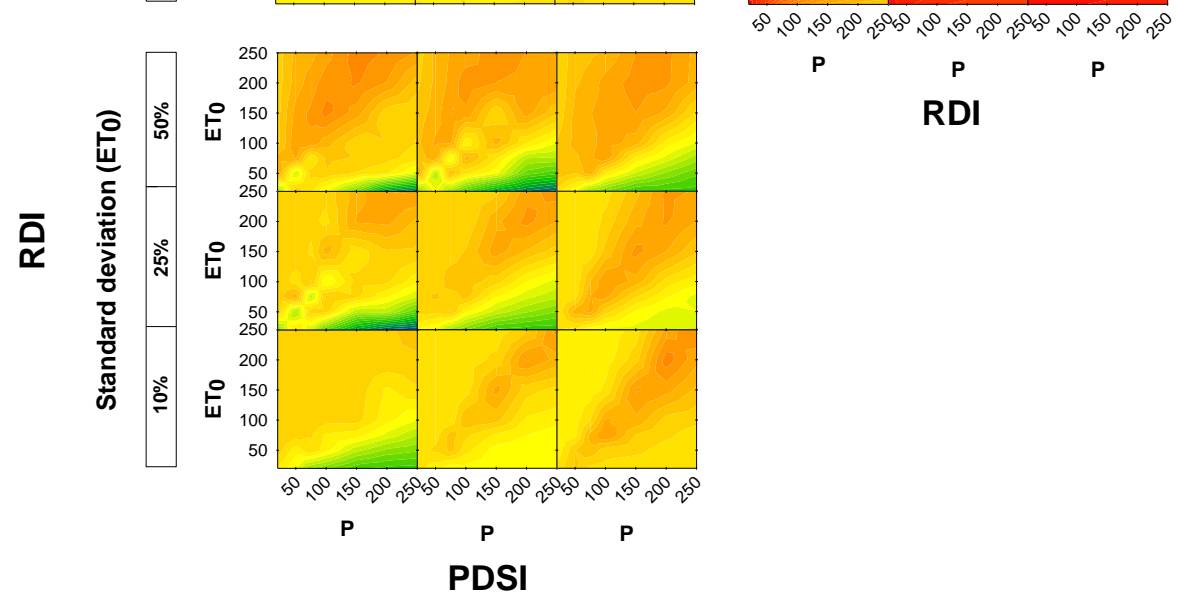

RDI

Supplementary Figure 2. Pearson's r correlations between the time series of the four different drought indices (PDSI, RDI, SPEI and SPDI) based on simulated P and ETo series of 100 years with different averages and standard deviations. The PDSI and the SPDI are obtained considering a soil water capacity equal to $500 \mathrm{~mm}$. 

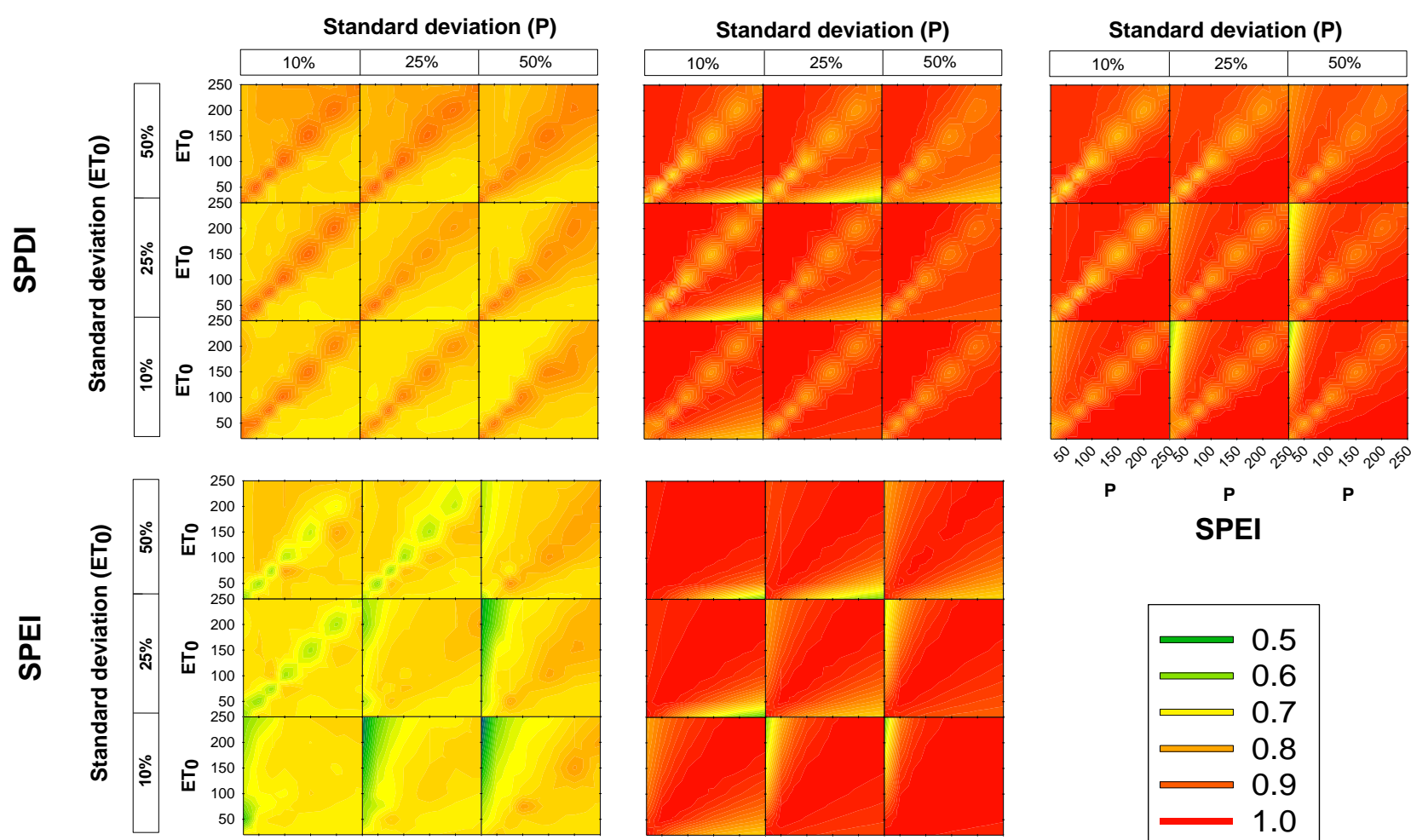

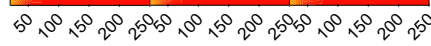

$P$

SPEI
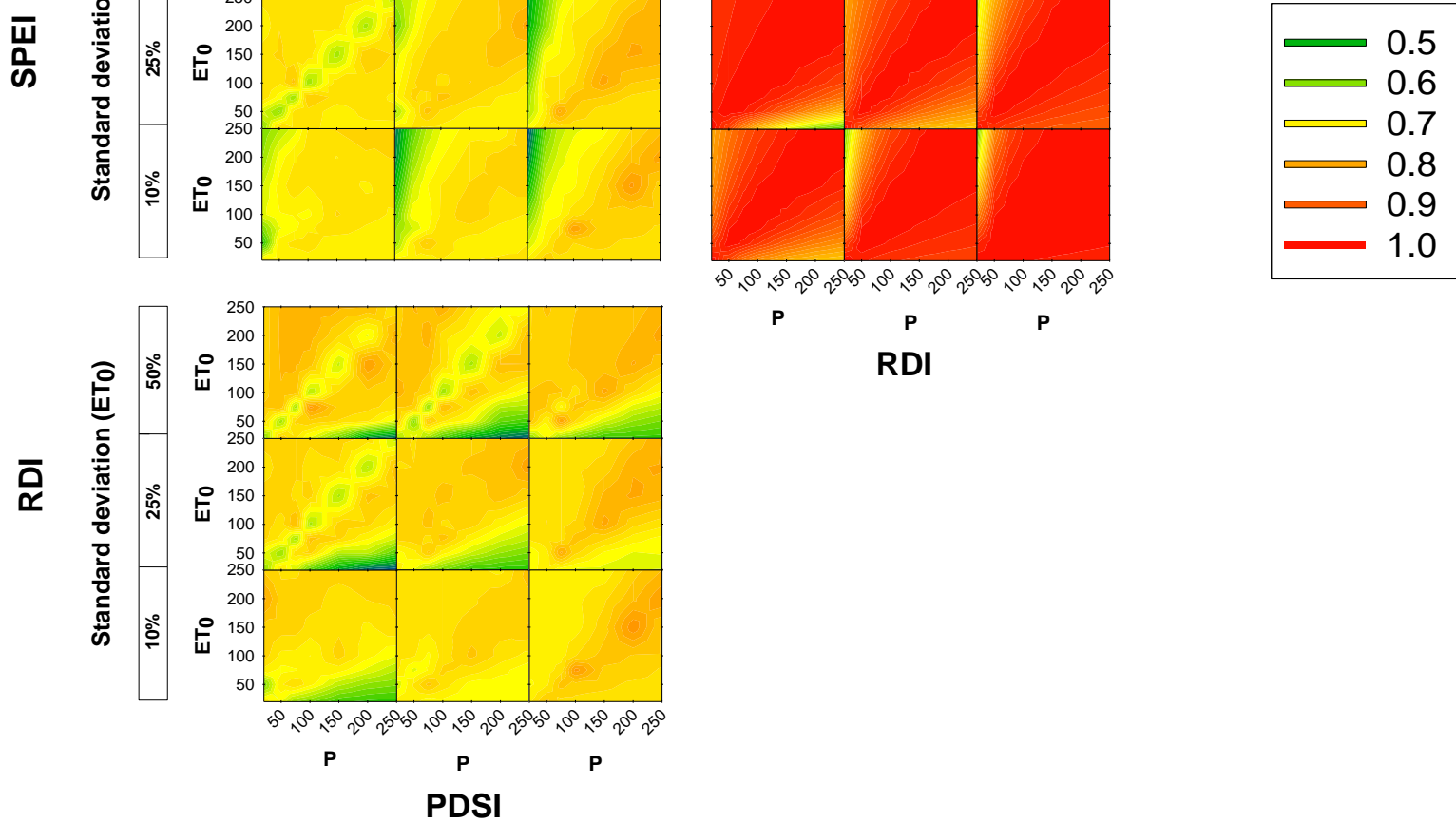

RDI

Supplementary Figure 3. Pearson's r correlations between the time series of the four different drought indices (PDSI, RDI, SPEI and SPDI) based on simulated P and ETo series of 100 years with different averages and standard deviations. The PDSI and the SPDI are obtained considering a soil water capacity equal to $2000 \mathrm{~mm}$. 
Precipitation

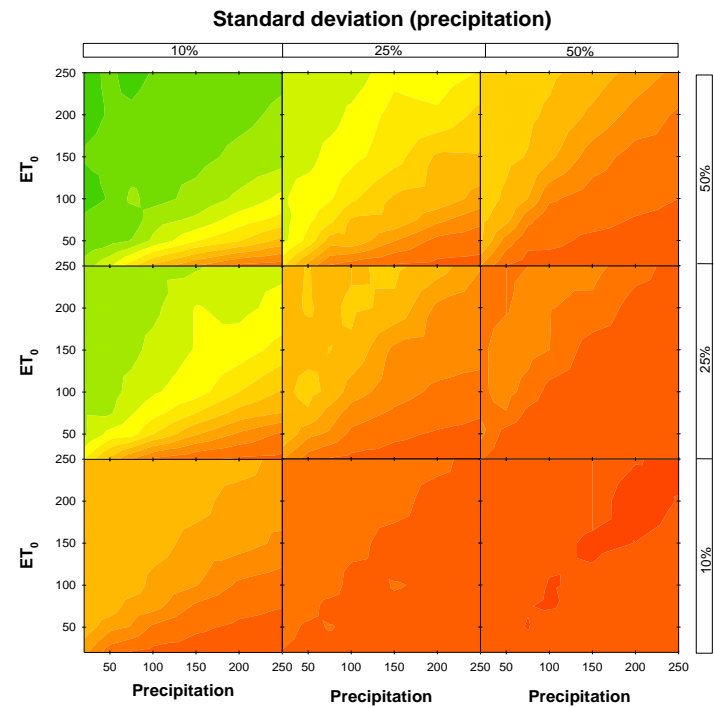

$\mathrm{ET}_{0}$

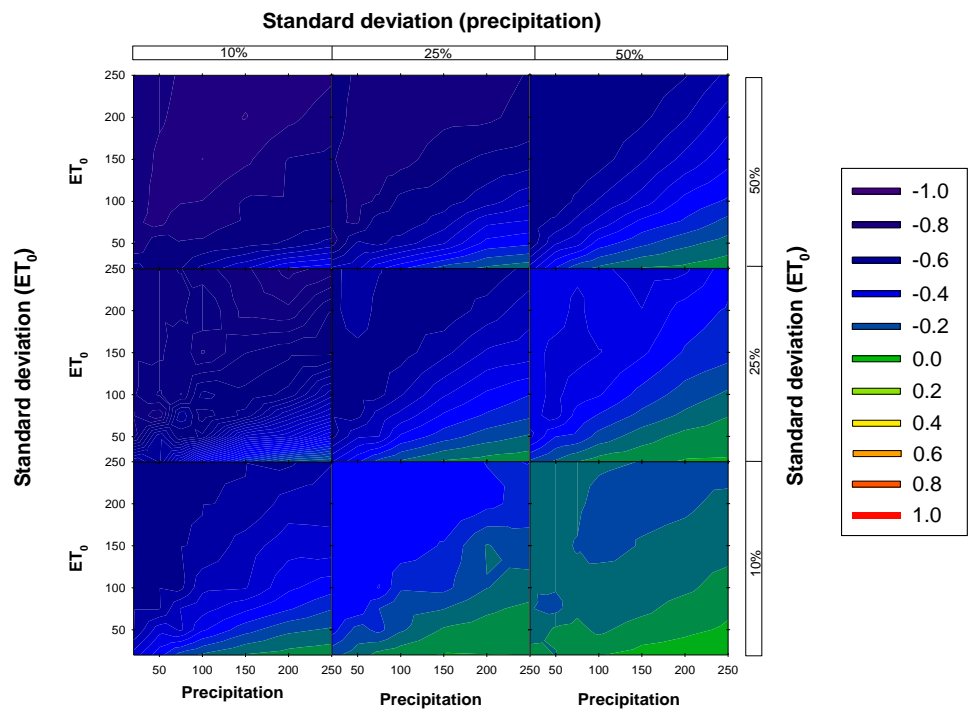

Supplementary Figure 4. Pearson's $r$ correlation coefficients between best correlated 1-24-month time-scale P and best correlated 1-24-month time-scale time-scale ETo and the PDSI from simulated series. Soil water capacity $=500 \mathrm{~mm}$. 
Precipitation

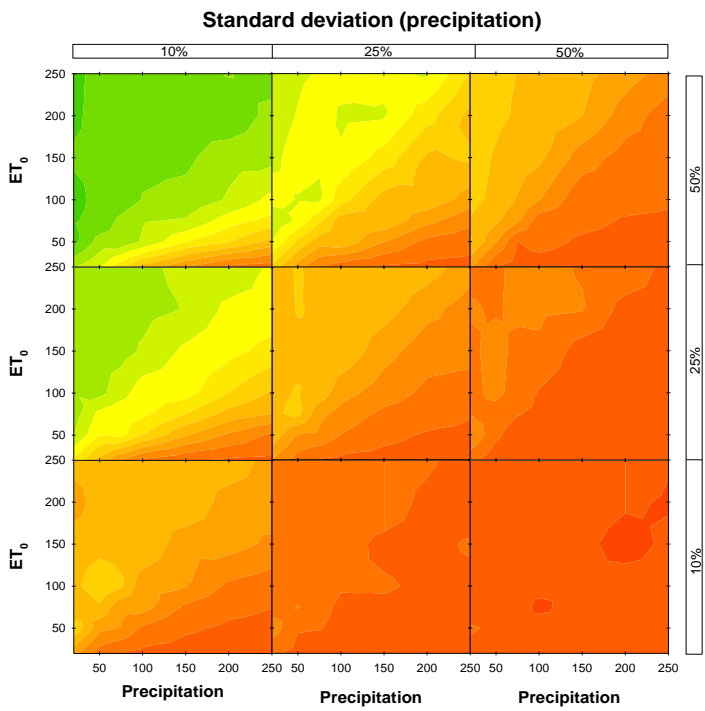

$\mathrm{ET}_{0}$

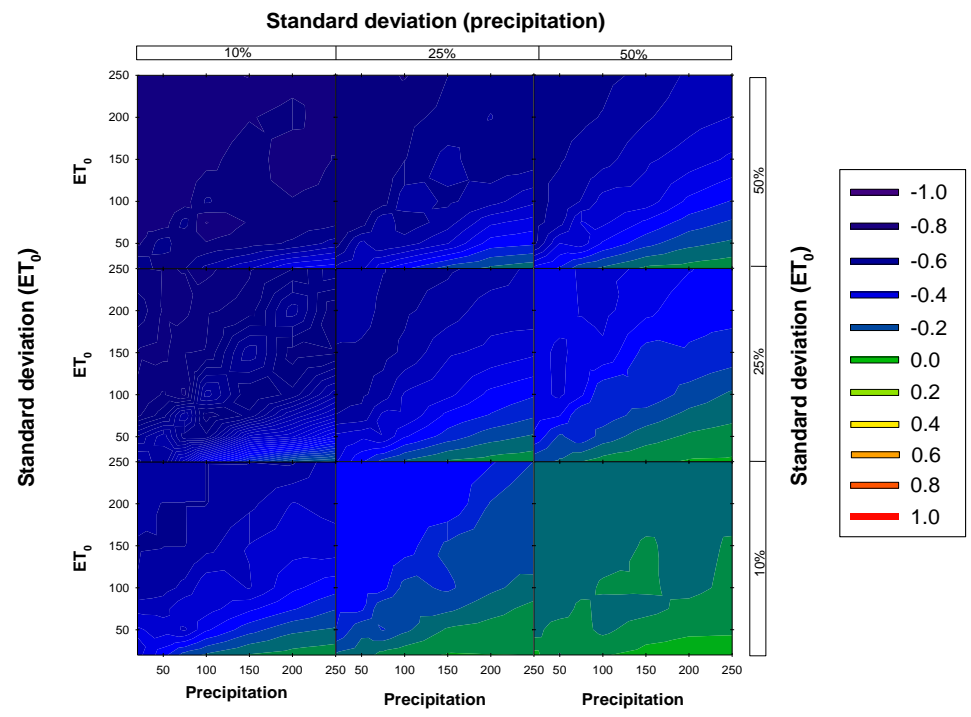

Supplementary Figure 5. Pearson's r correlation coefficients between best correlated 1-24-month time-scale $\mathrm{P}$ and best correlated 1-24-month time-scale time-scale ETo and the PDSI from simulated series. Soil water capacity $=2000 \mathrm{~mm}$. 
Precipitation

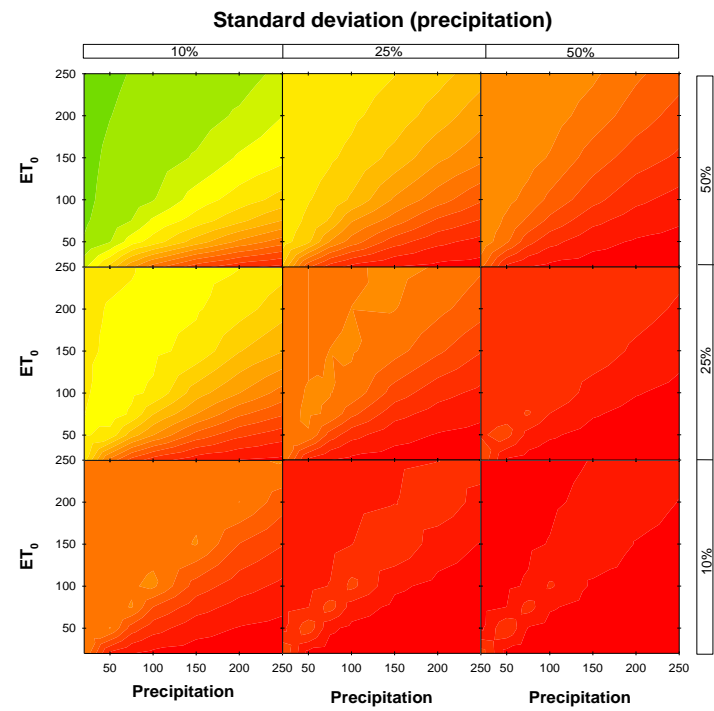

$\mathrm{ET}_{0}$

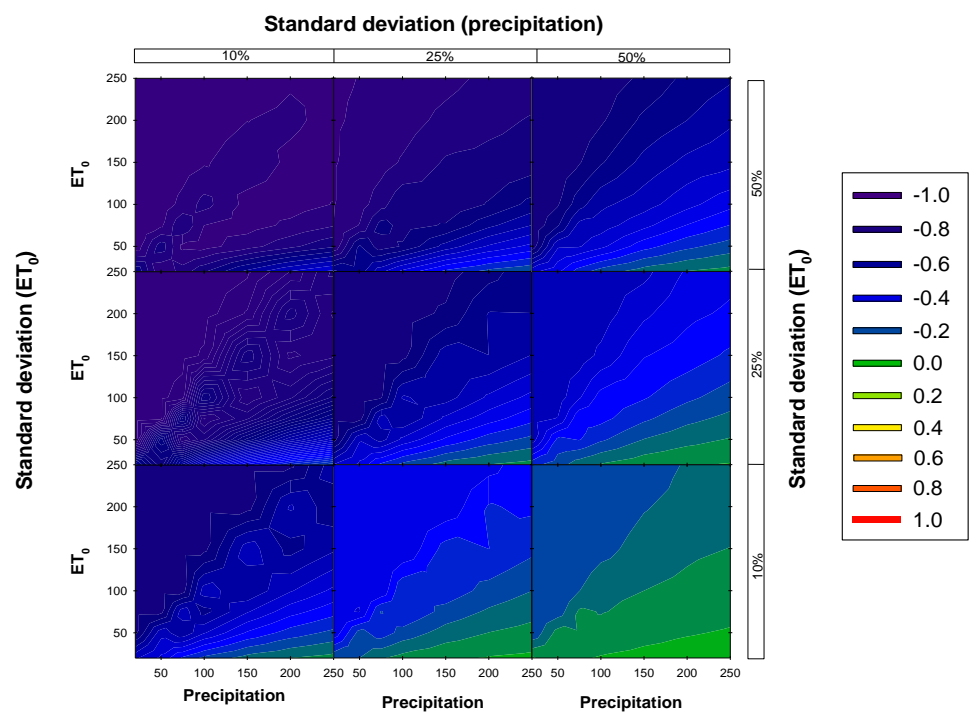

Supplementary Figure 6. Pearson's r correlation coefficients between 12-month P and 12- month ETo and the SPDI from simulated series. Soil water capacity $=500 \mathrm{~mm}$. 
Precipitation

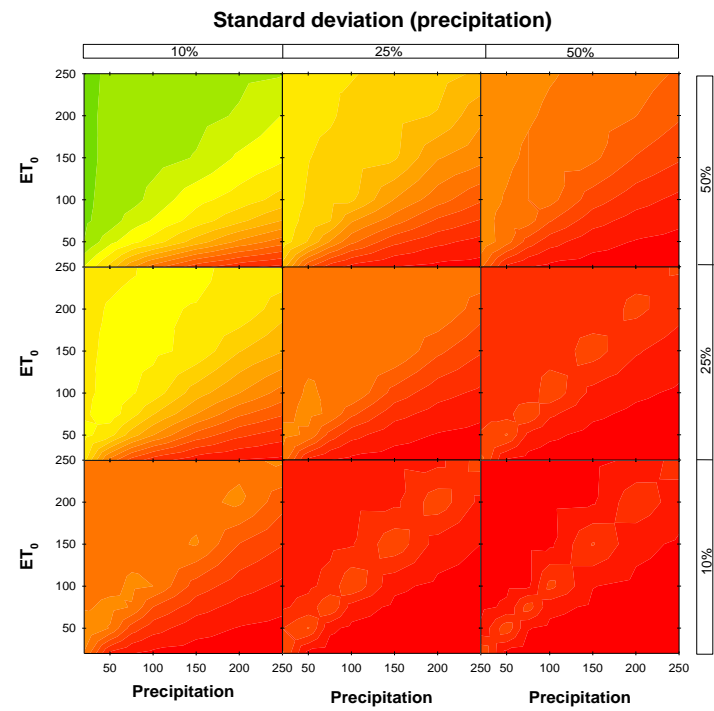

$\mathrm{ET}_{0}$

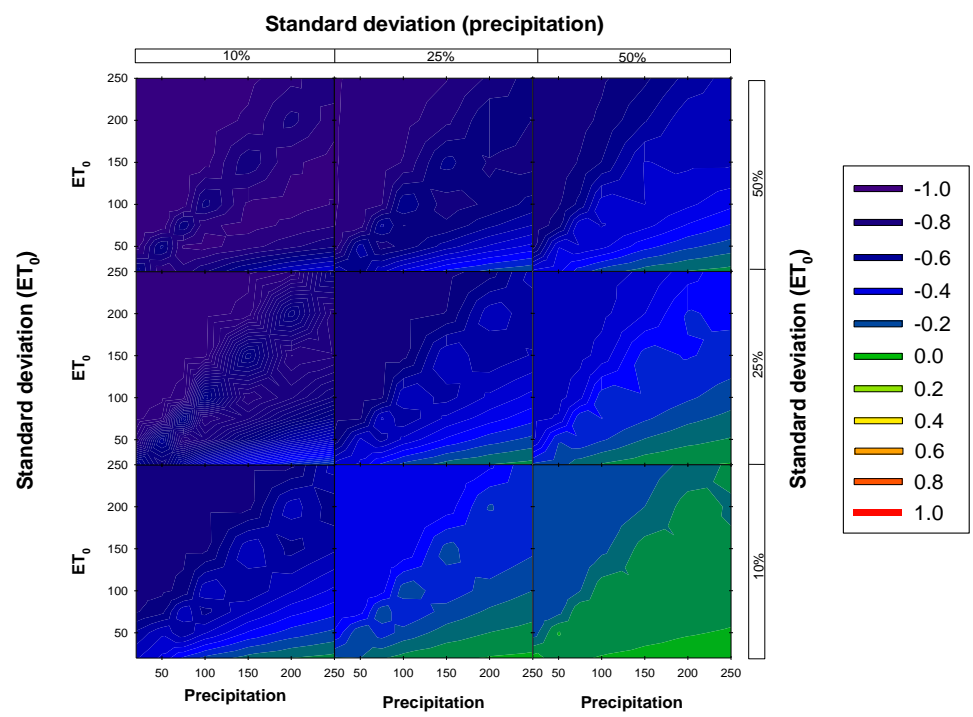

Supplementary Figure 7. Pearson's r correlation coefficients between 12-month P and 12- month ETo and the SPDI from simulated series. Soil water capacity $=2000 \mathrm{~mm}$. 
Precipitation

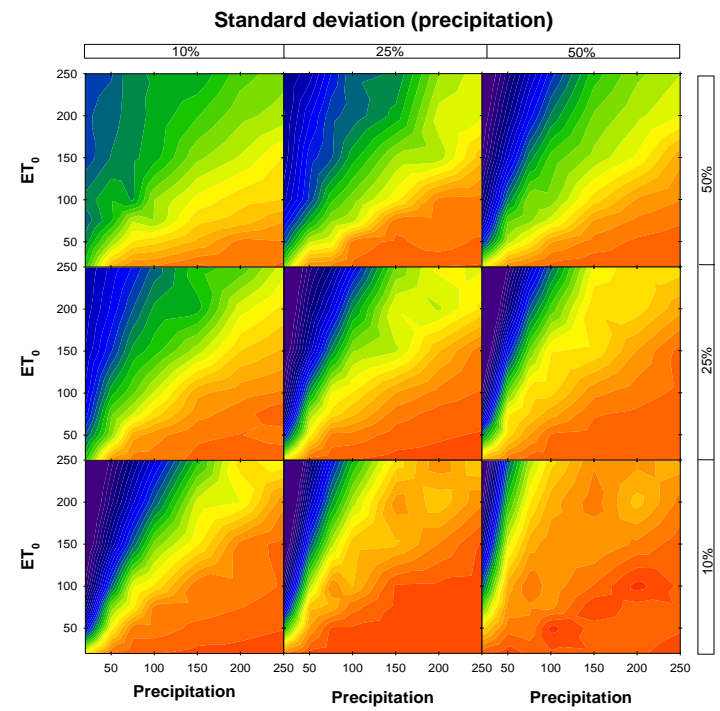

$\mathrm{ET}_{0}$

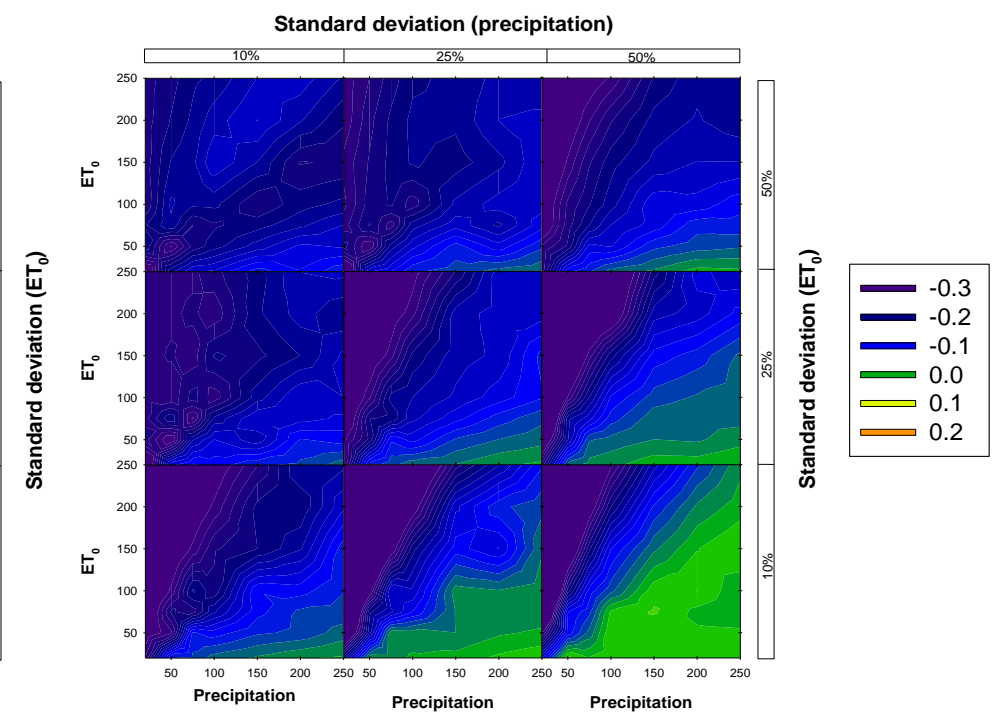

Supplementary Figure 8. Difference (in Pearson's r units) between correlation coefficients obtained with the SPEI vs. 12-month P and 12- month ETo and the PDSI vs. best correlated 1-24-month timescale $\mathrm{P}$ and best correlated 1-24-month time-scale ETo. The PDSI is obtained using a soil water capacity $=1000 \mathrm{~mm}$. 
Precipitation

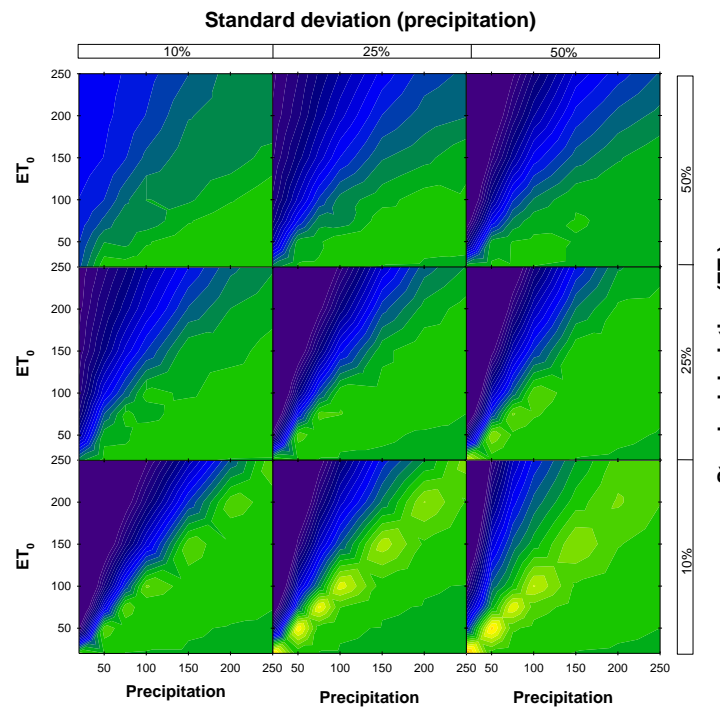

$\mathrm{ET}_{0}$

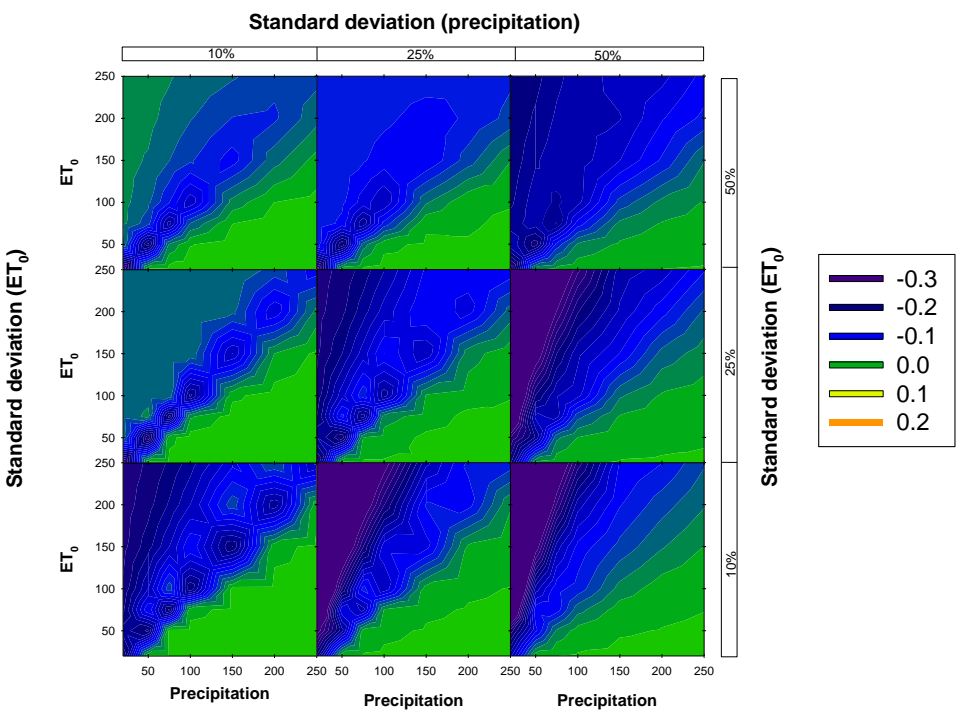

Supplementary Figure 9. Difference (in Pearson's $r$ units) between correlation coefficients obtained with the SPEI vs. 12-month P and 12- month ETo and the SPDI vs. 12-month P and 12- month ETo. The SPDI is obtained using a soil water capacity $=1000 \mathrm{~mm}$. 
Precipitation

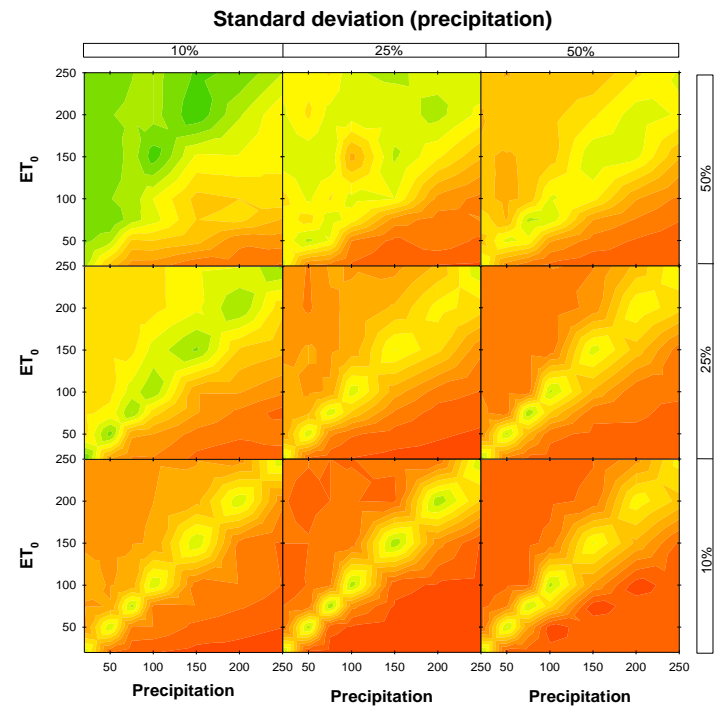

$\mathrm{ET}_{0}$

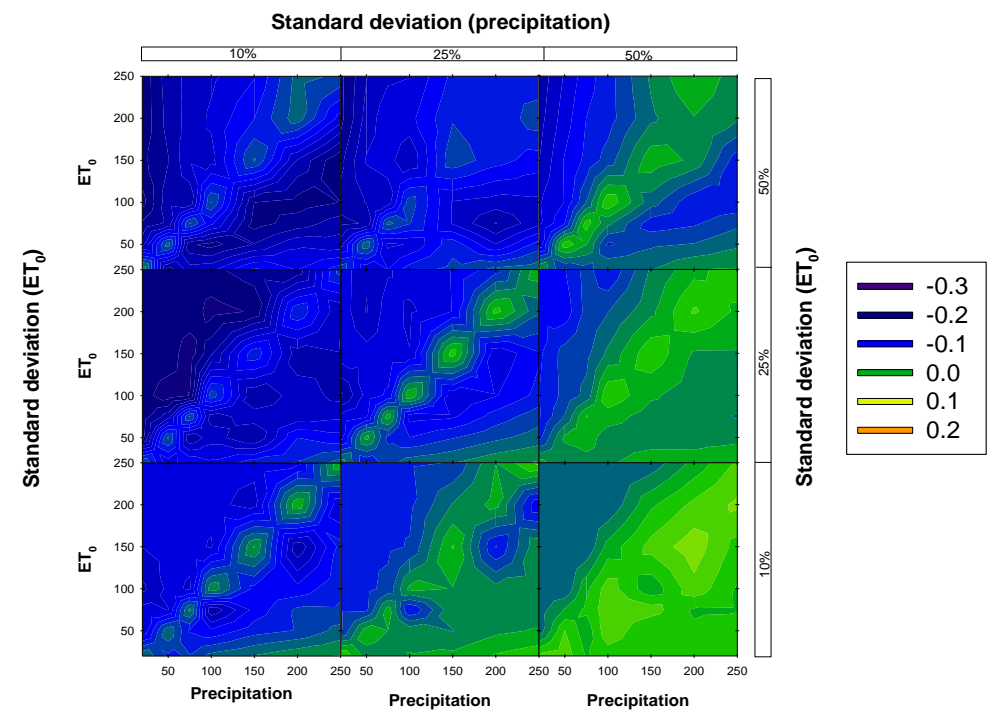

Supplementary Figure 10. Difference (in Pearson's r units) between correlation coefficients obtained with the SPDI vs. 12-month P and 12- month ETo and the PDSI vs. best correlated 1-24-month timescale $\mathrm{P}$ and best correlated 1-24-month time-scale ETo. The PDSI and the SPDI are obtained using a soil water capacity $=1000 \mathrm{~mm}$. 

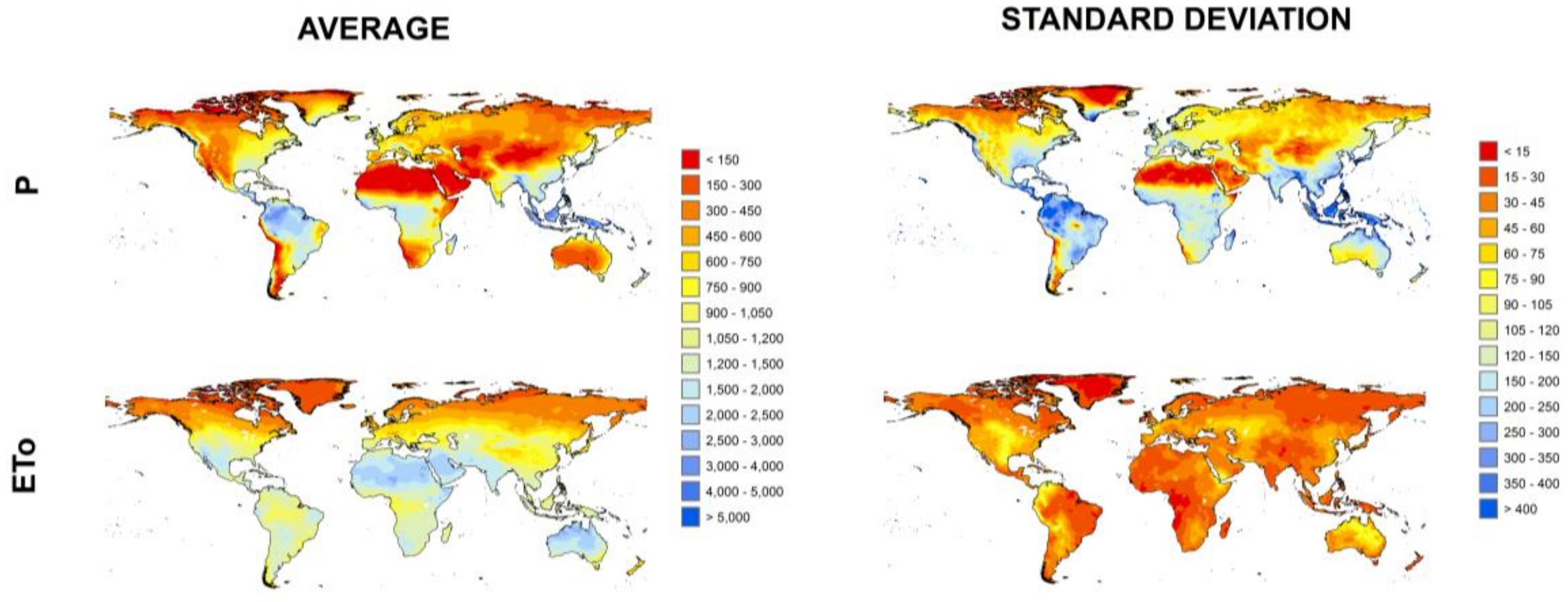

Supplementary Figure 11. Spatial distribution of 12-month average and standard deviation P and ETo at the global scale from the gridded CRU TS3.10.01 dataset. 

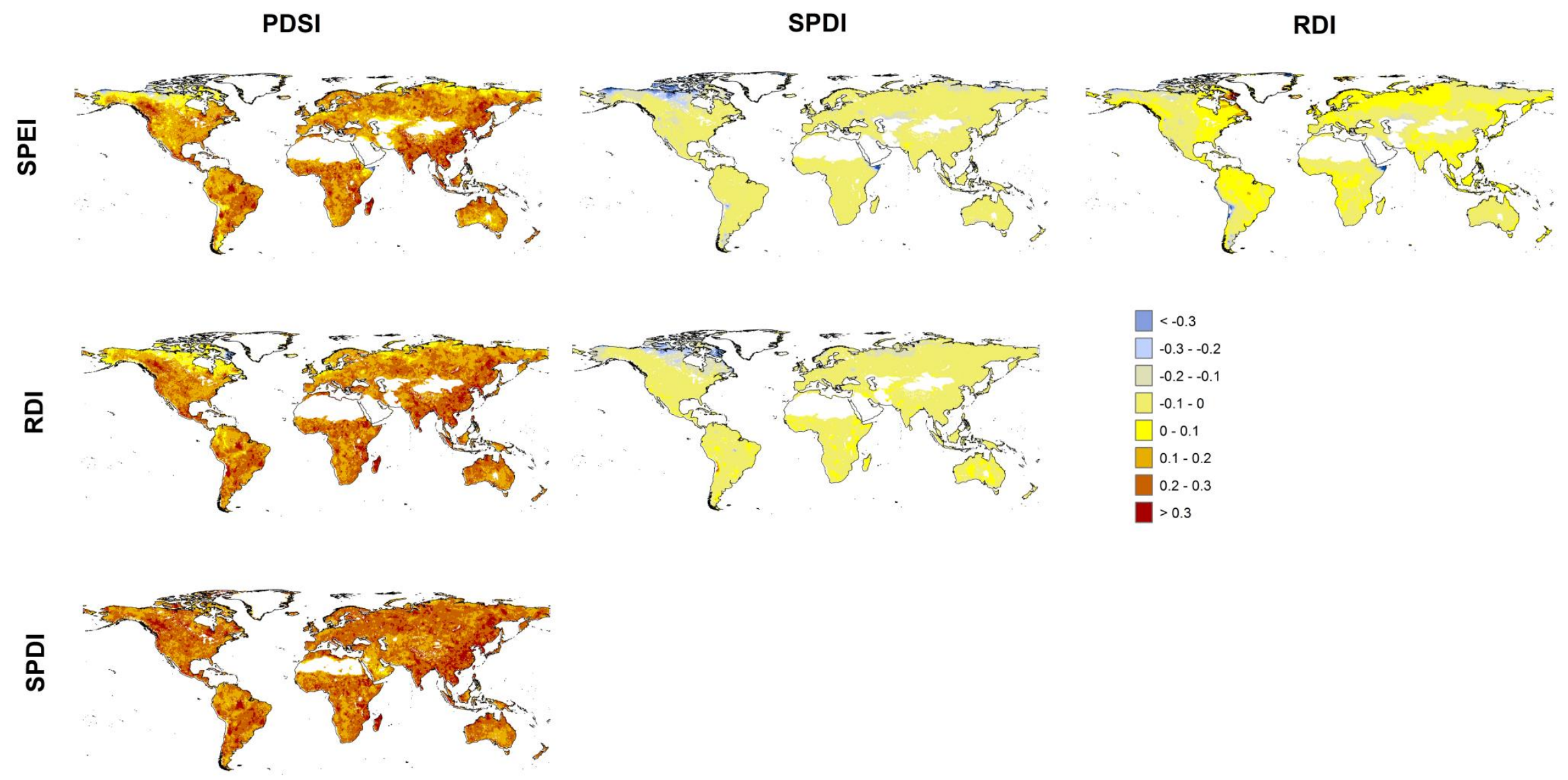

Supplementary Figure 12. Difference (in Pearson's $\mathrm{r}$ units) between correlation coefficients obtained with the four indices and P (12-month for SPEI, RDI and SPDI and best correlated 1-24-month time-scale P). 

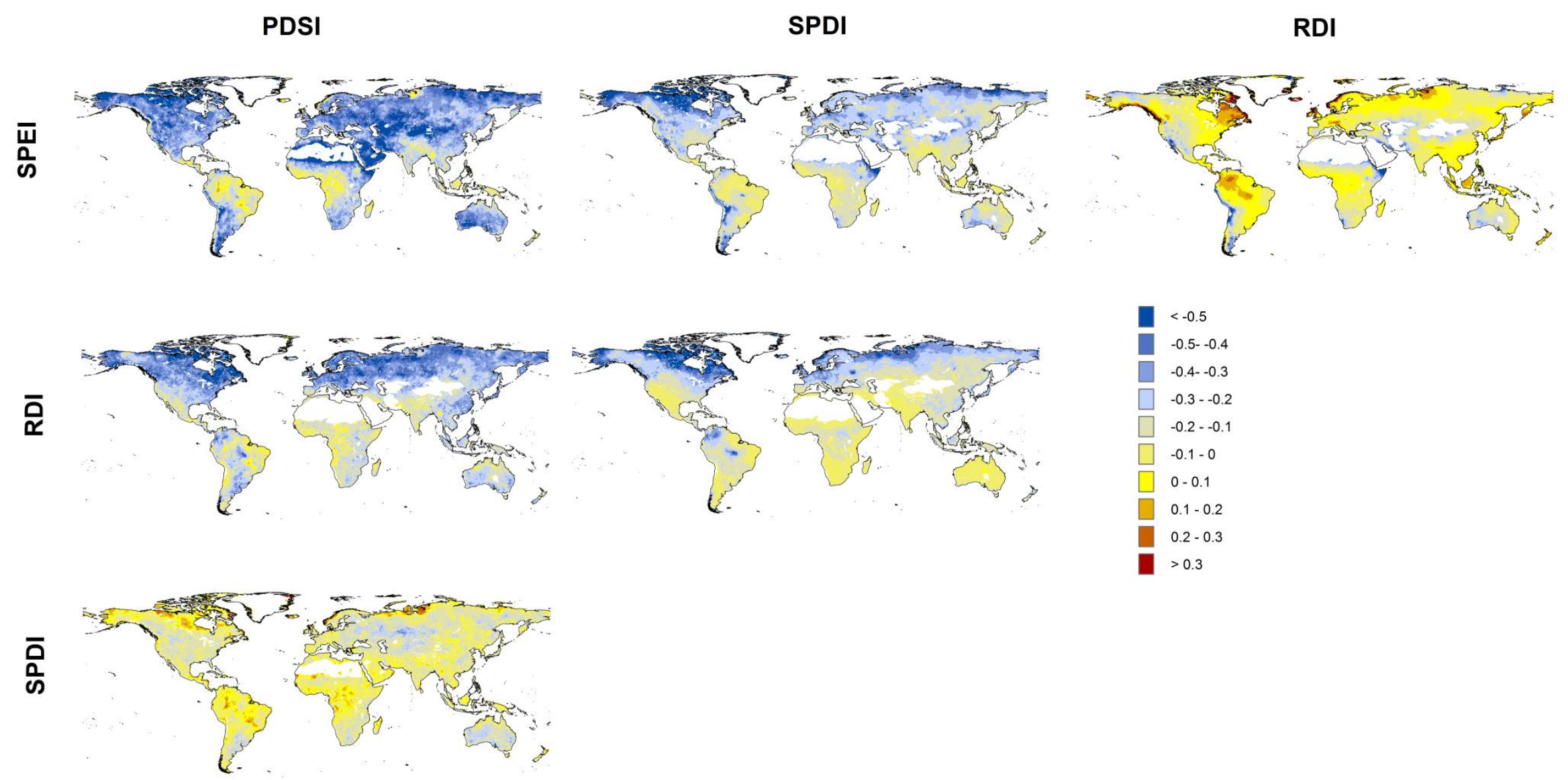

Supplementary Figure 13. Difference (in Pearson's r units) between correlation coefficients obtained with the four indices and ETo (12-month for SPEI, RDI and SPDI and best correlated 1-24-month time-scale ETo). 